\title{
Solid State Reaction Kinetics of Iron Oxide Using Hydrogen as a Reducing Agent
}

Amey A. Barde ${ }^{1^{*}}$, James F. Klausner ${ }^{2}$ and Renwei $\mathrm{Mei}^{3}$

1. Postdoctoral scholar, Department of Mechanical and Aerospace Engineering, University of California, Los Angeles, CA, USA. ${ }^{1}$

2. MSU Foundation Professor and Chair, Department of Mechanical Engineering, Michigan State University, East Lansing, MI, USA. ${ }^{2}$

3. Professor, Department of Mechanical and Aerospace Engineering, University of Florida, Gainesville, FL, USA.

*Corresponding Author: Phone: (352)-870-9096, E-mail:ameybarde@ucla.edu.

\section{Abstract}

The thermochemical reduction of metal oxides is important for fuel production using chemical looping processes as well as metal extraction from ore. In this study, reaction kinetics for the reduction of iron oxide using hydrogen as a reducing agent is studied. Experiments are conducted with the iron-silica Magnetically Stabilized Porous Structure (MSPS) for different reaction conditions, including reaction temperature, hydrogen inlet molar concentration, and hydrogen inlet flow rate. The reduction reaction is characterized by step-wise conversion of magnetite to elemental iron via wustite. Thus the reaction kinetics is governed by the coexistence of two reactions, magnetite to wustite and wustite to iron conversions. A one-dimensional plug flow isothermal kinetic model is proposed, and a numerical scheme is developed to solve the species transport and substrate conservation equations. The numerical scheme is used as a tool to calibrate the kinetic model, and the critical kinetic parameters, including activation energy, pre-exponent and order of reaction, are determined for both reactions. The reaction mechanism for both reactions is identified, and a transition in the reaction mechanism is captured with different models. The kinetic model shows good agreement with the experimental data for different operating conditions. This study provides a basis for scaling bench scale hydrogen reduction reactors to an industrial scale.

\section{Introduction}

The production of hydrogen using metal oxide thermochemical looping processes is gaining significant interest due to the high purity of hydrogen that can be achieved. Iron and its oxides are widely used as a reactive substrate in the two-step water splitting process to generate high purity hydrogen. Elemental iron reacts with steam during the

\footnotetext{
${ }^{1}$ This investigation was conducted while a PhD student at University of Florida.

2 This investigation was conducted while a professor at University of Florida. 
oxidation step to generate high purity hydrogen, and iron is converted to iron oxide. In order to recover elemental iron that can be used in a subsequent oxidation step, the iron oxide must be reduced. The extent to which the reduction reaction can be driven often limits the success of thermochemical looping, and thus it is important to gain an understanding of the reaction kinetics of iron oxide reduction. The reduction of iron oxides has been extensively investigated, predominantly for metallurgical applications to extract iron from its ores. It involves unidirectional conversion of higher iron oxide to lower oxide/elemental iron, rather than a consecutive oxidation and reduction of iron/iron oxide substrates in a looping process. In the looping process, which is the focus of this investigation, the oxidation reaction influences the subsequent reduction reaction through morphological changes in the reactive substrate, and this impact must be realized in the parametric study of the reduction reaction. Mehdizadeh et al. [1] synthesized a novel iron-silica Magnetically Stabilized Porous Structure (MSPS), which is a highly reactive metallic structure that maintains high hydrogen production over consecutive looping cycles at high temperature. They suggested that an iron-silica MSPS has a significant potential for industrial and chemical applications involving looping processes. Mehdizadeh et al. [2] developed a kinetic model for the oxidation reaction involving steam and iron-silica MSPS, and kinetic parameters were experimentally determined. Thus, a comprehensive parametric study of reduction kinetics for an iron-silica MSPS is in order. There are common gaseous reducing agents that can be considered for iron oxide reduction, including carbon monoxide, hydrogen, and Syngas. Industrial grade Syngas and/or fuel grade hydrogen are pragmatic reducing agents. The design of reactors using industrial grade Syngas and/or fuel grade hydrogen in two-step water splitting processes requires an understanding of the reduction kinetics using hydrogen as a reducing agent. Such looping processes provide an alternative to selective filtration for purifying hydrogen, and as an example they enable coal-to-Syngas-to-hydrogen conversion.

Several studies have analyzed the reduction of iron oxides (magnetite as well as hematite) using carbon monoxide, hydrogen, and Syngas as reducing agents, and findings of the selected studies are briefly discussed as a part of this investigation. Allen et al. [3] investigated structural and morphological changes in an iron-silica MSPS using TGA, SEM and HT-XRD analyses. The HT-XRD analysis was conducted for the iron oxide reduction using hydrogen as a reducing agent in the temperature range of 25$1000^{\circ} \mathrm{C}$. This analysis shows that wustite appears as an intermediate phase during the reduction reaction, beginning at $700{ }^{\circ} \mathrm{C}$, and it disappears at higher temperatures $\left(>\sim 930^{\circ} \mathrm{C}\right)$. These results are in agreement with the thermodynamic analysis of iron oxide reduction presented by the authors (Fig. 11.c, Ref. 3). The thermodynamic analysis predicts that the mole fraction of wustite at the end of the reduction reaction decreases as the total amount of hydrogen used during iron oxide reduction increases (Fig. 11.a-c, Ref. 3). Wagner et al. [4] studied the reduction of hematite using hydrogen 
and proposed the stepwise reduction of hematite to elemental iron through magnetite and wustite. Pineau et al. [5, 6] studied the reduction of hematite and magnetite using hydrogen at different temperatures. The activation energies were reported, and the reaction mechanism showed variations above and below the transition temperature. They also compared hydrogen and carbon monoxide, and found the former to be a better reducing agent based on the reduction rate. Reduction with carbon monoxide resulted in the formation of undesirable iron carbide and intermediate iron oxides. Lin et al. [7] studied temperature programmed reduction (TPR) of hematite and suggested the presence of two reactions; hematite to magnetite and magnetite to elemental iron. The reactions followed the unimolecular Avrami-Erofeev models, respectively. Mondal et al. [8] considered the reduction of hematite using carbon monoxide in the temperature range, $800-900{ }^{\circ} \mathrm{C}$. The presence of carbon and iron carbide was reported. Activation energies reported were in the range of $9.97-14.65 \mathrm{~kJ} / \mathrm{mol}$ for the different reactions involved. Bonalde et al. [9] investigated the reduction of hematite using hydrogen, carbon monoxide, and a mixture of both gases as reducing agents. A kinetic model was proposed for a reduction reaction involving each reducing agent.

The reduction of iron oxide using methane $[10,11]$ was extensively studied for its application in chemical looping combustion. The dependence of reaction rate on temperature, particle size, and secondary additives was analyzed. Piotrowski et al. [12] studied the influence of a reducing agent gas composition on the kinetics of iron oxide reduction. The reaction mechanism and activation energy were determined for reduction of iron oxide using carbon monoxide, hydrogen, and Syngas as reducing agents. Fruehan [13] considered the reduction of iron oxide using solid carbon. Stepwise reduction of hematite to elemental iron via an intermediate wustite phase was observed. The effects of carbon content, source of the carbon, particle size, total pressure, and reaction temperature, on the rate of reduction were analyzed. Tiernan et al. [14] investigated the reduction of hematite and magnetite using hydrogen under nonisothermal conditions. They used constant rate thermal analysis (CRTA) and temperature programmed reduction (TPR) methods. CRTA was cited as the preferred method in order to maintain uniform temperature and pressure conditions across the reactive sample. This allowed for more straightforward interpretation of the kinetic data. The reduction of hematite proceeded via intermediate magnetite phase. Reduction reactions followed phase boundary and random nucleation reaction mechanisms, with activation energies of $96 \mathrm{~kJ} / \mathrm{mol}$ and $59-69 \mathrm{~kJ} / \mathrm{mol}$, respectively.

Turkdogan and Vinters [15-17] extensively studied the reduction of hematite pellets in hydrogen, carbon monoxide, and Syngas environments. Experiments were conducted at various operating conditions with variable reaction temperature, gas inlet flow rate, and particle size. Three rate controlling mechanisms were proposed: uniform internal reduction, limiting mixed control, and diffusion through the porous iron layer. In 
limiting mixed control regime, reduction reaction is controlled by gas diffusion in iron oxide pores and chemical reaction on pore walls of iron oxide. The extent to which mechanism is dominant is largely dependent on the particle size and reduction temperature. The porous reactive substrate was characterized in terms of pore area, pore radius, and pore diffusivity.

Sastri et al. [18] investigated hydrogen reduction of pure and doped hematite at various temperatures in the range $300-500{ }^{\circ} \mathrm{C}$. Samples of doped hematite were prepared by adding metal oxides, including $\mathrm{Li}_{2} \mathrm{O}, \mathrm{MgO}, \mathrm{Al}_{2} \mathrm{O}_{3}, \mathrm{In}_{2} \mathrm{O}_{3}, \mathrm{TiO}_{2}$, and $\mathrm{CaO}$ to pure hematite. Addition of metal oxides retarded the rate of reduction due to structural changes in the reactive substrate. A sudden change in the slope of the rate curve at a relative weight loss of $11 \%$ was observed during reduction of pure hematite. This weight loss corresponds to a quantitative conversion of hematite to magnetite. Thus, hematite was reduced to elemental iron in a stepwise manner. Fresh metal additives, including iron and nickel, had a catalytic effect on the reduction of hematite. A commonality among the iron reduction experiments is the finding that iron oxide is reduced to iron in a stepwise manner, revealing the coexistence of multiple reactions. Hydrogen appears to be the preferred reducing agent based on reaction rate and extent of reaction.

This work focuses on the development of a robust kinetic model for the reduction of iron-silica MSPS using hydrogen as a reducing agent in a laboratory scale plug flow reactor. Experiments are conducted to study the rate of reduction under different operating conditions, including hydrogen inlet flow rate $\left(Q_{o}\right)$, hydrogen inlet molar concentration $\left(C_{o}\right)$, and reaction temperature $(T)$. A one dimensional plug flow isothermal kinetic model is developed to determine key kinetic parameters, including activation energy, pre-exponent, and order of reaction. Macroscopic and microscopic mass distributions of iron oxide in the structure are investigated and their impacts on reaction kinetics are discussed. A concept of transition point is introduced to capture the shift in chemical reactions and reaction mechanisms during the reduction process. The kinetic model shows good agreement with experimental measurements for different operating conditions and can be used as a design tool to scale chemical looping reactors. 


\section{Nomenclature}

\begin{tabular}{|cl|}
\hline$\dot{r}_{j}$ & Rate of reaction $\left(\mathrm{mol} / \mathrm{m}^{3} \mathrm{~s}\right)$ \\
$k_{o}$ & Pre-exponent $\left(\left(\mathrm{mol} / \mathrm{m}^{3}\right)^{(1-n)} / \mathrm{s}\right)$ \\
$E_{a}$ & Activation energy $(\mathrm{J} / \mathrm{mol})$ \\
$R$ & Universal gas constant $(\mathrm{J} / \mathrm{mol} \mathrm{K})$ \\
$T$ & Reaction temperature $(\mathrm{K})$ \\
$n$ & Order of reaction \\
$x_{i}$ & Fractional conversion of reactive substrate, $i$ \\
$f\left(x_{i}\right)$ & Dimensionless function defining reaction mechanism \\
$A$ & Arrhenius rate constant $\left(\left(\mathrm{mol} / \mathrm{m}^{3}\right)^{(1-\mathrm{n})} / \mathrm{s}\right)$ \\
$C_{j}$ & Molar concentration of species $j\left(\mathrm{~mol} / \mathrm{m}^{3}\right)$ \\
$C_{o}$ & Hydrogen inlet molar concentration $\left(\mathrm{mol} / \mathrm{m}^{3}\right)$ \\
$\dot{Q}$ & Volumetric flow rate $\left(\mathrm{m}^{3} / \mathrm{s}\right)$ \\
$Q_{o}$ & Hydrogen inlet flow rate $(\mathrm{SLPM})$ \\
$V_{C V}$ & Control volume $\left(\mathrm{m}^{3}\right)$ \\
$M$ & Molecular weight $(\mathrm{kg} / \mathrm{mol})$ \\
$m$ & Mass of reactive substrate $(\mathrm{kg})$ \\
$\beta_{i}$ & Conversion factor for reactive substrate, $i$ \\
$U$ & Velocity of gas $(\mathrm{m} / \mathrm{s})$ \\
$\rho_{i}$ & Density of reactive substrate, $i\left(\mathrm{~kg} / \mathrm{m}^{3}\right)$ \\
$\rho_{i}{ }^{*}$ & Dimensionless apparent density reactive substrate, $i$ \\
$z$ & Spatial coordinate along bed length $(\mathrm{m})$ \\
$L$ & Bed length $(\mathrm{m})$ \\
$\eta$ & Dimensionless bed length \\
\end{tabular}

\section{Experimental facility}

\section{1. $\quad$ Reactor}

Figure 1 shows the experimental configuration for the iron oxide reduction investigation. A $4.6 \mathrm{~cm}$ ID quartz tube serves as the reactor. The reactor tube is $45 \mathrm{~cm}$ in length and is fitted with an integrated frit that acts as a support for the MSPS. The tube can sustain temperatures as high as $1100^{\circ} \mathrm{C}$. It is supported by gland seals at both ends and silicon O-rings are used for sealing. The O-ring can sustain temperatures up to $250^{\circ} \mathrm{C}$ and are thus placed far from the heated section. A radiative ceramic heater serves as the primary heating source and can raise the bed temperature up to $1100^{\circ} \mathrm{C}$. It is necessary to keep the gas line (carrying hydrogen and helium), steam line and reactor at sufficiently high temperature to avoid condensation of steam and drop in bed temperature due to inflow of relatively cold gases. Two rectangular magnets are 
installed on either side of the reactor to help prepare the magnetically stabilized ironsilica structure. The magnets are only needed for the initial preparation of the porous reactive structure. Once the structure is formed, it maintains its integrity over long periods of operation [1].

A steam line connects the steam generator to the inlet of the reactor. An inline steam generator coupled with a syringe pump generates the steam. The steam line is heated with a rope heater to maintain steam above the saturation temperature. A gas line carries various gases to the reactor, including, argon, hydrogen and helium. Individual gas lines are equipped with a gas flow controller to supply a manifold. The manifold is connected to the reactor inlet, and a pre-heater is installed on the gas line to maintain its temperature in the range of $150-200^{\circ} \mathrm{C}$.

\subsection{Separation of product gases}

The gaseous products of the oxidation and reduction reactions are comprised of steam and hydrogen. In order to ensure an accurate measurement of hydrogen and protect the electronic instruments, steam is condensed and separated from hydrogen. A shell and tube type condenser is installed which condenses the steam while allowing only hydrogen to pass to the reactor outlet flow meter.

\subsection{Measurement devices and data acquisition system}

A gas flow meter (Alicat M-20SLPM) is used to record the flow rate of hydrogen. The output gases are analyzed using a mass spectrometer (Hiden Analytical HPR-20). The mass spectrometer is calibrated with known flow rates of different gases and serves as verification for the hydrogen flow rate. A K-type thermocouple is installed to measure the bed temperature. The thermocouple is connected to a PID controller, which controls the bed temperature. A Data acquisition system, comprised of NI 6211DAQ board coupled with LabVIEW, is used to capture the hydrogen flow rate signal from the Alicat flow meter at the reactor outlet.

\section{Experimental procedure}

A 100 gram sample of iron powder (size: $63-75 \mu \mathrm{m}$ ) is mixed with silica powder (size: $75-106 \mu \mathrm{m}$ ) in a 2:1 ratio (silica: iron) by apparent volume. The thermocouple position is fixed at the desired bed location prior to loading the powder into the reactor. Once the powder sample is loaded, the bed is fluidized by passing inert gas (argon) through the bed. A well-fluidized bed is then subjected to a stationary magnetic field, and the flow of argon is simultaneously cut off. The iron particles align themselves in the direction of the magnetic field. The neighboring iron chains repel each other due to similar polarity, and silica particles get settled between neighboring iron chains to act as a buffer. This inhibits sintering of chains and maintains greater surface area to drive 
chemical reactions. Since the Curie temperature of iron is $770^{\circ} \mathrm{C}$, it is necessary to keep the bed temperature below this threshold. Moreover, the flow of steam should be low enough to keep the bed intact. First oxidation is performed at $600{ }^{\circ} \mathrm{C}$ and steam is supplied at a rate $0.5 \mathrm{~g} / \mathrm{min}$. After the bed is stabilized, the flow rate and bed temperature are raised to higher values. Then oxidation continues at $800{ }^{\circ} \mathrm{C}$ with a steam flow rate of $2 \mathrm{~g} / \mathrm{min}$. The reduction reaction is performed at different operating conditions, which includes variations in reaction temperature, hydrogen inlet flow rate, and hydrogen inlet molar concentration. Helium is mixed with hydrogen at the inlet of the reactor to change the inlet molar concentration. The experimental rate of steam generation is computed based on the flow rate of unreacted hydrogen measured by the flowmeter at the reactor outlet. Once the MSPS is synthesized, it is used for subsequent looping cycles, and there is no need to repeat the synthesis process, unless a reactor failure occurs.

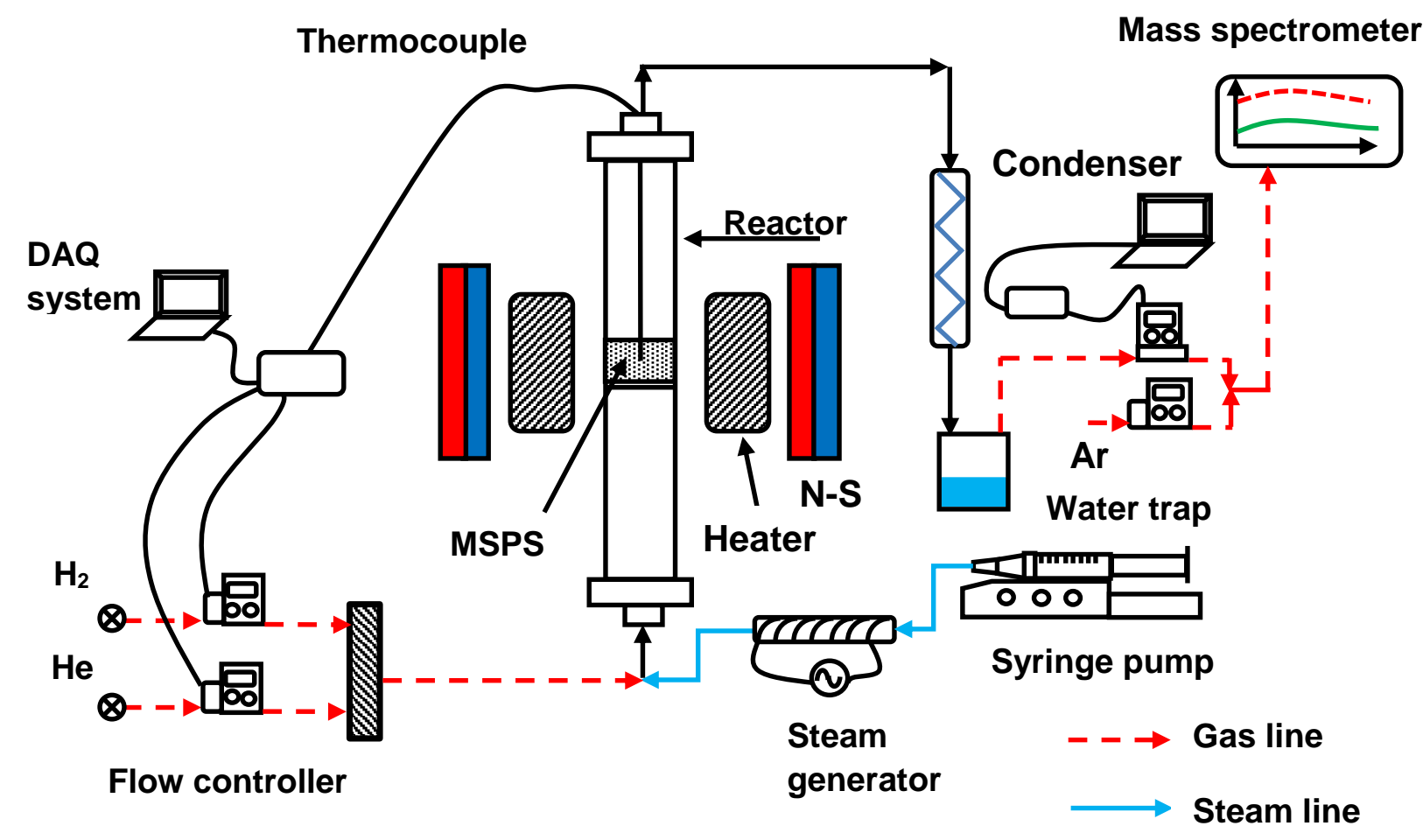

Figure 1. Experimental facility investigating redox reactions with a magnetically stabilized iron-silica porous structure.

The iron silica MSPS, synthesized during hydrogen reduction, exhibits contraction in the radial direction during the first four cycles. Such behavior is not observed when carbon monoxide is used as a reducing agent [1,2]; thus contraction behavior is 
specific to reduction using hydrogen. The MSPS structure stabilizes after four cycles and no further change in the diameter is observed for subsequent cycles. Detailed structural characterization of an iron-silica MSPS is discussed independently [1]

\section{Results and discussion}

Experiments were conducted to measure the rate and extent of MSPS reduction with hydrogen as a reducing agent at different operating conditions including reaction temperature, hydrogen inlet flow rate, and hydrogen inlet molar concentration. The dependence of the reduction reaction on these operating parameters is discussed and their role in kinetic modeling is analyzed. Table 1 summarizes the different operating conditions for MSPS reduction.

Table 1. Summary of operating conditions for iron based MSPS reduction with hydrogen as a reducing agent

\begin{tabular}{|c|c|c|c|c|}
\hline $\begin{array}{c}\text { Cycle } \\
\text { no. }\end{array}$ & $\begin{array}{c}\text { Reaction } \\
\text { temperature } \\
\left({ }^{\circ} \mathrm{C}\right)\end{array}$ & $\begin{array}{c}\text { Inlet flow rate } \\
\mathrm{H}_{2}, \mathrm{He}(\mathrm{SLPM})\end{array}$ & $\begin{array}{c}\text { Hydrogen inlet } \\
\text { molar } \\
\text { concentration } \\
\left(\mathrm{mol} / \mathrm{m}^{3}\right)\end{array}$ & Control variables \\
\hline 1 & 800 & $1.5,0$ & 11.36 & Flow rate \\
\hline 2 & 800 & $2.0,0.0$ & 11.36 & $\begin{array}{c}\text { Flow rate, inlet molar } \\
\text { concentration, } \\
\text { temperature }\end{array}$ \\
\hline 3 & 800 & $1.5,0.5$ & 8.56 & Inlet molar concentration \\
\hline 4 & 800 & $1.0,1.0$ & 5.68 & Inlet molar concentration \\
\hline 5 & 800 & $0.5,1.5$ & 2.84 & Inlet molar concentration \\
\hline 6 & 900 & $2.0,0.0$ & 11.36 & Reaction temperature \\
\hline 7 & 1000 & $2.0,0.0$ & 11.36 & Reaction temperature \\
\hline
\end{tabular}

\subsection{Reaction rate dependence on hydrogen inlet flow rate $\left(Q_{o}\right)$}

The hydrogen inlet flow rate, $Q_{o}$ is an important operating parameter that governs the rate of reduction. Increasing $Q_{o}$ increases the average concentration of hydrogen within the reactive structure, resulting in an enhanced rate of reaction. Figure 2 shows the rate of steam generation during reduction of the iron based MSPS structure for a hydrogen inlet flow rate of 1.5 and 2 SLPM, at $800^{\circ} \mathrm{C}$. It is observed that the peak rate of steam generation is increased and a higher rate of reaction is achieved with an increase in $Q_{o}$ during the early stages of the reaction. At the later stages, there is no noticeable difference in the rate of reaction. 


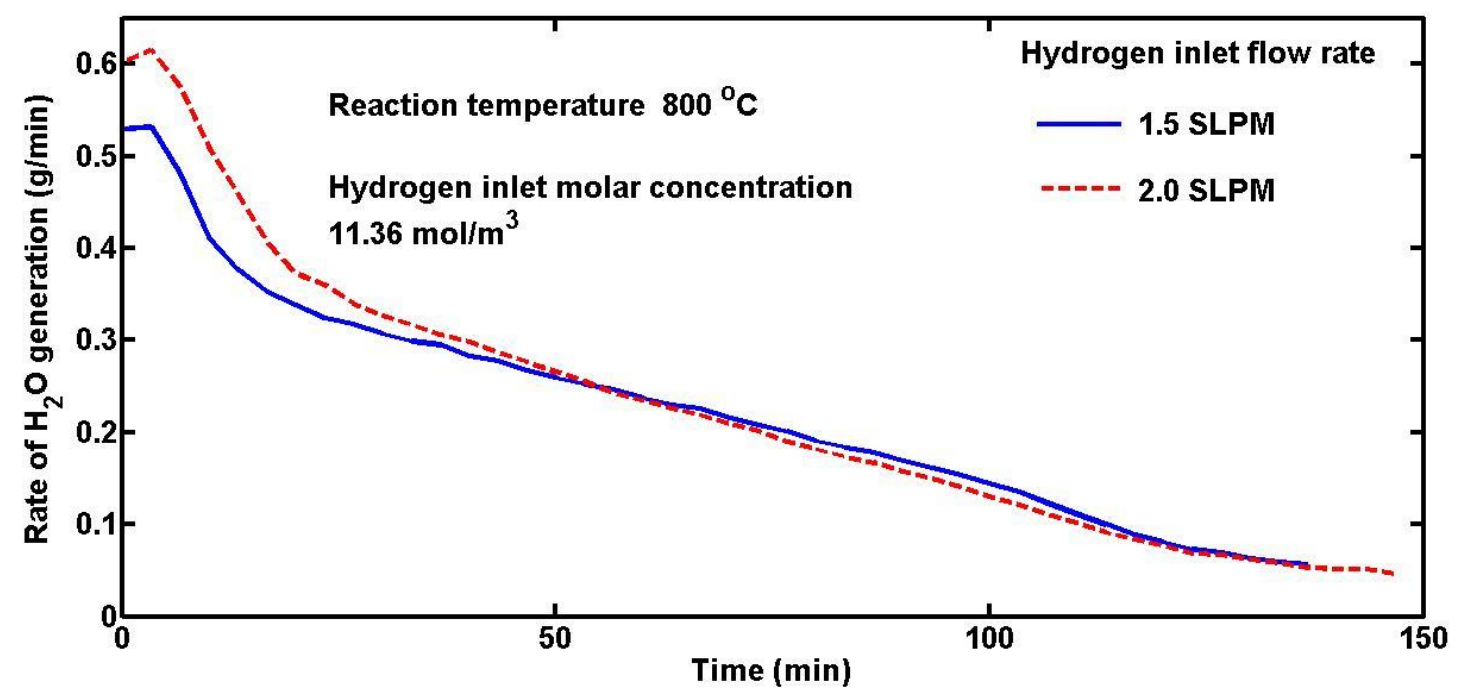

Figure 2. Rate of steam generation during MSPS reduction for a hydrogen inlet flow rate of 1.5 and 2.0 SLPM at $800^{\circ} \mathrm{C}$.

\subsection{Reaction rate dependence on hydrogen inlet molar concentration $\left(C_{o}\right)$}

The hydrogen inlet molar concentration, $C_{o}$ is another important parameter that governs the rate of the MSPS reduction reaction. For an open system, the local molar concentration is $C_{j}=\frac{\dot{n}_{j}}{\dot{Q}}$, where $j$ denotes the species. An increase in $C_{o}$ provides for a higher number of hydrogen molecules per unit volume to participate in the local reduction reaction, increasing the probability of a reaction between hydrogen and the oxygen in the iron oxide lattice. Experiments were conducted at different $C_{o}$ values, varying from 2.84 to $11.36 \mathrm{~mol} / \mathrm{m}^{3}$, at $800{ }^{\circ} \mathrm{C}$ (Figure 3). The hydrogen inlet molar concentration was varied by adding helium at the inlet of the reactor, while keeping the total gas inlet flow rate constant, at 2 SLPM. Figure 3 shows a substantial increase in the peak rate of steam generation from $\sim 0.15 \mathrm{~g} / \mathrm{min}$ to $\sim 0.6 \mathrm{~g} / \mathrm{min}$ with increasing molar concentration of 2.84 to $11.36 \mathrm{~mol} / \mathrm{m}^{3}$. Moreover, a significant gain in the average rate of reduction is observed with an increase in hydrogen inlet molar concentration. In the early stages, higher rate of reaction for higher $C_{o}$ results in consumption of significant iron oxide mass. Thus, for higher $C_{o}$, the lack of available reactive mass in later stages leads to a decrease in the reaction rate. These experimental measurements are used to determine the order of reaction. 


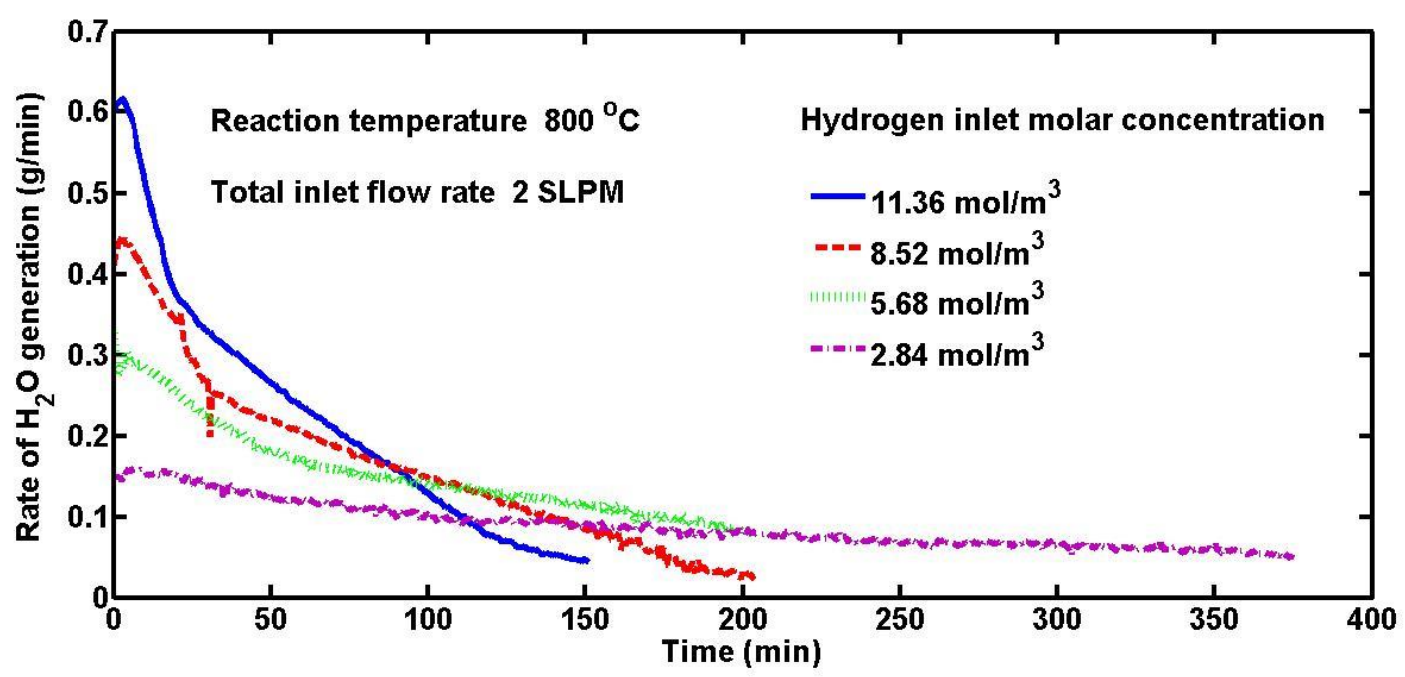

Figure 3. The rate of steam generation during MSPS reduction with different hydrogen inlet molar concentration at $800^{\circ} \mathrm{C}$ and total gas inlet flow rate of 2 SLPM.

\subsection{Reaction rate dependence on temperature $(T)$}

The rate of reaction increases exponentially with increasing reaction temperature, and thus the dependence of reaction kinetics on temperature is of fundamental interest. Experimental measurements at different reaction temperatures are used to determine the activation energy and pre-exponent. Experiments were conducted at different reaction temperatures in the range of $800-1000{ }^{\circ} \mathrm{C}$ with a hydrogen inlet flow rate of 2 SLPM (Figure 4). During the early stages of the reaction, it is observed that the reaction temperature has a pronounced influence on the rate of steam production.

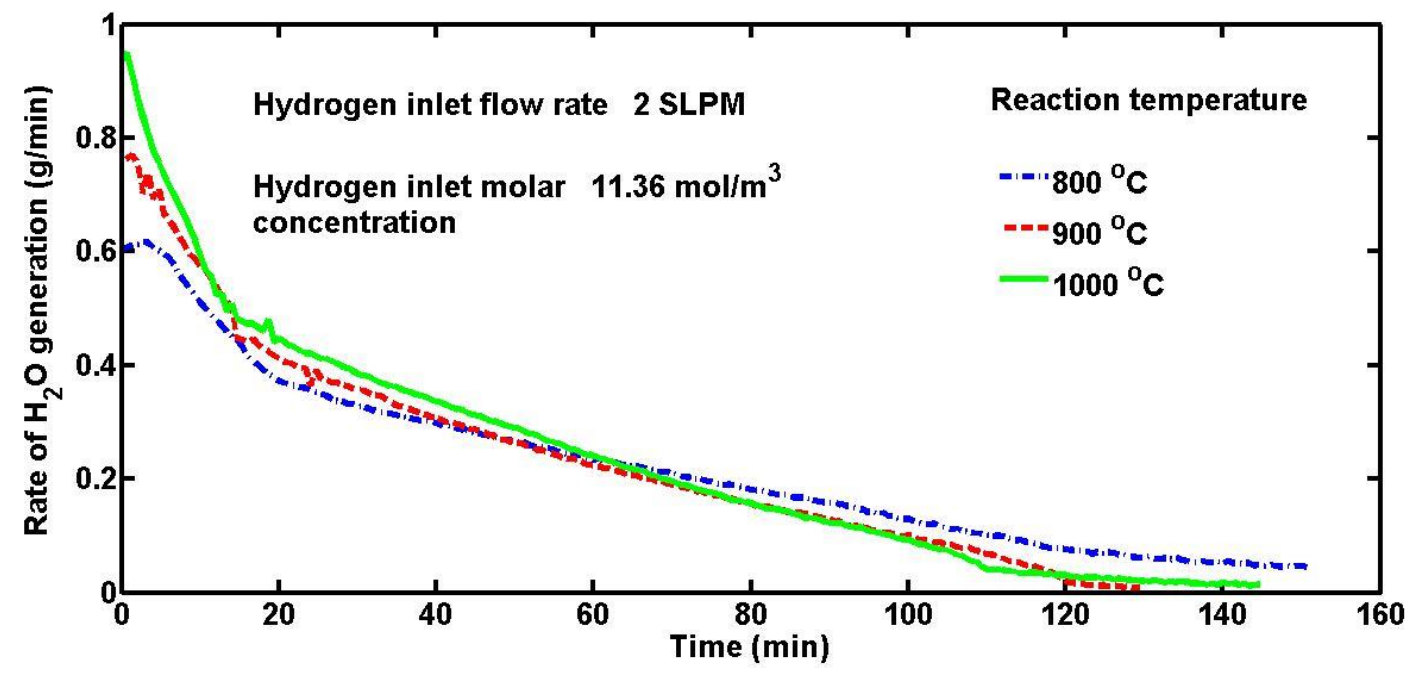

Figure 4. Rate of steam generation during MSPS reduction with reaction temperatures of $800,900, \& 1000^{\circ} \mathrm{C}$ and a hydrogen inlet flow rate of 2 SLPM. 
The experimental measurements for different operating conditions show a sharp and sudden change in the slope of the rate of reduction at a specific time. A similar phenomenon was reported by Wagner et al. [4] for the reduction of hematite using hydrogen as a reducing agent. The sudden slope change in the rate curve was attributed to the complete conversion from higher oxide to lower oxides. This mechanistic hypothesis is used as a basis to identify the transition point for the parametric modeling of the reaction kinetics over the full range of experimental conditions; details are discussed in the next section.

\section{Kinetic modeling}

Kinetic modeling is important to predict the rate at which the reaction proceeds based on local thermodynamic conditions. It not only provides physical insight into the reaction but also serves as an important tool that can be used for reactor design and scale up. The overall reduction of magnetite using hydrogen as a reducing agent can be represented as,

$$
\mathrm{Fe}_{3} \mathrm{O}_{4}+4 \mathrm{H}_{2} \rightarrow 3 \mathrm{Fe}+4 \mathrm{H}_{2} \mathrm{O}
$$

A single step conversion of magnetite to elemental iron is too simplistic to capture the correct kinetics since the reduction of magnetite likely takes place through intermediate steps. As mentioned earlier, prior studies have identified the presence of wustite during the reduction of magnetite. Thus the reaction sequence for the reduction of magnetite is characterized by the forward operation of two reactions,

Magnetite-wustite conversion

$$
\mathrm{Fe}_{3} \mathrm{O}_{4}+\mathrm{H}_{2} \rightarrow 3 \mathrm{FeO}+\mathrm{H}_{2} \mathrm{O}
$$

Wustite-Fe conversion

$$
\mathrm{FeO}+\mathrm{H}_{2} \rightarrow \mathrm{Fe}+\mathrm{H}_{2} \mathrm{O}
$$

These two reactions occur simultaneously, but their extent and rate of reaction may be different and dynamic in nature. Experimental measurements of rate of steam generation using hydrogen as a reductant reflect the combined effect of both reactions, and it is necessary to develop an appropriate kinetic model that captures the kinetics of both. 


\subsection{Governing equations}

For a solid state chemical reaction given by (2) and (3), the rate of reaction can be represented as,

$$
\dot{r}_{j}=k_{o, i} \operatorname{Exp}\left(-E a_{i} / R T\right) f\left(x_{i}\right) C_{j}^{n}
$$

The rate of reaction, $\dot{r}\left(\mathrm{~mol} / \mathrm{m}^{3} \mathrm{~s}\right)$, is the rate of generation or consumption of species $\left.j, k_{o, i}\left(\mathrm{~mol} / \mathrm{m}^{3}\right)^{(1-\mathrm{n})} / \mathrm{s}\right)$ is a pre-exponent and $E a_{i}(\mathrm{~J} / \mathrm{mol})$ is the activation energy. $f\left(x_{i}\right)$ is a dimensionless function that represents the reaction mechanism, $x_{i}$ is the fractional conversion of reactive material, $C_{j}\left(\mathrm{~mol} / \mathrm{m}^{3}\right)$ is the molar concentration. The subscript $j$ denotes the species, $j=1$ for hydrogen and $j=2$ for steam. The subscript $i$ denotes the phase of the iron oxide substrate, $i=1$ for magnetite and $i=2$ for wustite. The superscript $n$ denotes the order of reaction.

For an open system, the species transport equation is solved using a numerical scheme to find concentration of the species. Here, the only gradients considered are along the length of the reactor, which is equivalent to a plug flow assumption. Thus, the one dimensional species transport equation is expressed as,

$$
\frac{\partial C_{j}}{\partial t}+U \frac{\partial C_{j}}{\partial z}=\dot{r}_{j}
$$

The sink/source term, $\dot{r}$ inherently has dependence on the fractional conversion of reactive material, and the substrate conservation equation,

$$
\frac{d x_{i}}{d t}=\beta_{i} k_{o, i} \exp \left(-E a_{i} / R T\right) f\left(x_{i}\right) C_{j}^{n},
$$

is solved to determine $x_{i}$, where $\beta_{i}$, is a conversion factor for the oxide substrate, magnetite or wustite,

$$
\beta_{i}=\frac{M_{i} V_{C V}}{m_{i}}
$$

(See Appendix A for derivation of Eqs. 6 \& 7) The governing equations are implicitly interdependent and require an appropriate numerical scheme to obtain a solution. The solution requires realistic initial and boundary conditions, and these must be dealt with appropriately. 


\subsection{Iron oxide mass distribution}

There are two different considerations for iron oxide distribution that require attention: macroscopic and microscopic distribution. Macroscopic distribution represents the distribution of mass across the bed as a function of bed length. Microscopic distribution is associated with the distribution of iron oxide within a single particle. Macroscopic and microscopic mass distributions have a significant influence on the reaction kinetics, and their impact is discussed in this section.

\subsubsection{Macroscopic distribution of mass}

The oxidation step plays an important role in the macroscopic distribution of iron oxide phases, wustite and magnetite, within the reactor bed. According to the kinetic model for steam oxidation of iron-silica MSPS [2], a gradient in the fractional conversion of magnetite $\left(x_{1}\right)$ exists within a bed where, $x_{1}$ is maximum at the bed inlet, $x_{1}(z=0)=1$ and it progressively decreases along the bed length. During oxidation, the inlet of the bed receives steam with maximum molar concentration, and progressively the steam concentration is diluted along the bed length by the production of hydrogen. During the oxidation step it is more likely that the elemental iron near the bed inlet, which receives fresh steam, is completely converted to magnetite, and the conversion extent will progressively decline along the bed length due to a decrease in steam concentration. Thus there is a need to estimate the distribution of iron oxide along the bed length following oxidation so that a realistic initial condition can be specified to solve (Eqs. 4 to 7). A straightforward approach is to use the kinetic model for steam oxidation to determine the macroscopic distribution of iron oxide phases at the beginning of each reduction reaction listed in Table 1. However, it requires computation of kinetic parameters for both reduction and oxidation reactions simultaneously, using iterative experimental measurements of reaction rate for different operating conditions. This method is very complex to implement and is likely to introduce errors in the computation of kinetic parameters. Instead, a mathematically simplified, robust approach based on the well-established 'integral method' used in boundary layer analysis is adopted. A framework is established to determine a macroscopic distribution of iron oxide in terms of its apparent density $(\rho)$. A polynomial function is proposed to define the apparent density along the bed length (Eq. 9). Specified physical constraints (Table B.1, Appendix B) are identified, based on fundamental physics, to determine the unknown coefficients. A thermodynamic analysis of steam oxidation of iron reveals the presence of different iron oxide phases at the end of the oxidation step [19, 20]. A morphological analysis of a pure iron specimen, after steam oxidation in the temperature range from $650-750^{\circ} \mathrm{C}[21,22]$, confirms the presence of different iron oxide phases. Thus, experimental measurements of hydrogen production during steam oxidation of iron- 
silica MSPS reflects conversion of iron into different iron oxide phases (predominantly magnetite and wustite), and it is difficult to accurately determine the mass of individual iron oxide phases. The assumption that magnetite and wustite are the only oxide phases to participate in the reduction reaction is ideal. Thus, a pragmatic approach is adopted to assume the presence of a single oxide phase, magnetite, at the end of the oxidation step. Mehdizadeh et al. [2] developed a kinetic model for steam oxidation involving single step conversion of iron into magnetite. This kinetic model showed good agreement with the experimental measurements of the hydrogen production rate during water splitting, which supports the premise that magnetite is the primary constituent at the end of the oxidation step. Moreover, to achieve maximum conversion of iron into magnetite, the oxidation step was continued for sufficiently long duration until the hydrogen generation rate dropped to a very low threshold ( 0.05 SLPM).

The dimensionless apparent density of magnetite $\left(\rho^{*}\right)$ at any point within the reactive bed is defined as

$$
\rho^{*}=\frac{\text { Local apparent density of magnetite, } \rho(\mathrm{z})}{\text { Maximum apparent density of magnetite, } \rho_{\max }}
$$

where, $\rho_{\max }$ is the maximum apparent density of magnetite which assumes the complete conversion of iron into magnetite. A polynomial function is used to represent the apparent density distribution of magnetite in non-dimensional form,

$$
\rho^{*}=a \eta^{3}+b \eta^{2}+c \eta+d
$$

$\rho *$ is the dimensionless apparent density and $\eta=z / L$ is the dimensionless length of the bed. Unknown constants in Eq. 9 are computed by applying appropriate boundary conditions and the apparent density distribution of magnetite is computed for reduction reactions listed in Table 1. A detailed analysis is provided in Appendix B, and coefficients a, b, and c are listed in Table B.2 for different initial mass of magnetite within the reactor.

\subsubsection{Microscopic Distribution}

The microscopic distribution of iron oxide phases within a single reactive particle has been investigated for various applications. Signorini et al. [23] reported morphological and structural characterization of iron/iron oxide core-shell nanoparticles. Iron nanoparticles were synthesized using the IGC (inert gas condensation) technique. These nanoparticles were initially exposed to oxygen and then to air for 24 hours, to form an iron oxide shell surrounding an iron core. XRD and XAS diagnostic techniques 
were used to detect the presence of iron/iron oxide phases within a single nanoparticle. Kuhn et al. [24] studied structural and magnetic properties of core-shell iron/iron oxide nanoparticles. A core-shell structure was achieved by oxidizing iron nanoparticles in oxygen and air environments. XRD analysis showed the presence of $\alpha-\mathrm{Fe}$ and iron oxide phases within a nanoparticle. In TEM images (Figs. 1 and 2, Ref. 24), spherical nanoparticles with a distinct iron core and iron oxide shell are visible. Bahgat and Khedr [25] studied the magnetic behavior and morphological changes during isothermal reduction of single magnetite crystal using hydrogen as a reducing agent. Different iron oxide phases are visible within single magnetite crystal in photomicrographs at different reduction extents. At $20 \%$ reduction, an outer layer of porous wustite and inner layer of magnetite were visible. A core-shell structure composed of an outer layer of wustite with a magnetite core were observed at $40 \%$ extent of reduction. As the magnetite crystal is reduced to $80 \%$, islands of wustite trapped in metallic iron were observed. Iron based catalysts are extensively used in the Haber-Bosch process for industrial scale ammonia synthesis [26]. Synthesis of the catalyst involves reduction of the catalyst precursor (magnetite), using reducing agents including Syngas and hydrogen. During the reduction reaction, a core shell structure is developed within a catalyst particle (Fig. 24, Ref. 26). A core of magnetite surrounded by shells of wustite and elemental iron, separated by prominent interfaces, is distinctly visible.

Different studies involving morphological analysis of iron/iron oxide particles have confirmed the co-existence of different iron oxide phase within a single reactive particle. The morphology of reactive particles evolves as the oxidation/reduction process progresses, causing transition between iron oxide phases. In the current study, analysis of the experimental reduction data shows an abrupt change in the slope of the rate of reaction at a particular time, denoted as the transition point. This transition is indicative of different physical phenomenon driving the reaction before and after. It is hypothesized that the change in the reaction mechanism at the transition point is related to the microscopic distribution of iron oxide within a particle.

Consider a spherical iron particle subjected to oxidation with steam as shown in Figure 5. Mehdizadeh et al. [2] showed that the reaction mechanism initially follows a surface controlled reaction and then transitions into a diffusion controlled reaction. Thus the outer region of the sphere is likely oxidized completely to magnetite, while the core of the iron particle is partially oxidized to wustite as depicted in Figure 5. The microscopic distribution of iron oxide phases within the particle, magnetite and wustite, and their mass in the particle is governed by the thermodynamic conditions observed during the oxidation step. 


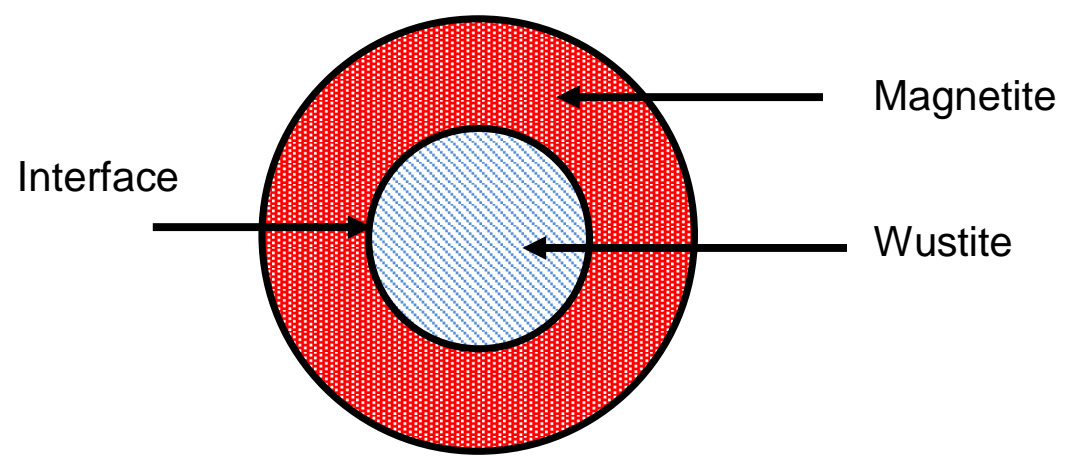

Figure 5. Postulated ideal distribution of magnetite and wustite within a single particle.

When such an ideal particle is subjected to chemical reduction, magnetite in the outer region is converted to iron via wustite. Thus reaction kinetics is governed by the presence of two reactions, magnetite $\rightarrow$ wustite and wustite $\rightarrow F e$. Once magnetite is converted to wustite (the reaction front reaches the interface), the only oxide phase remaining within the particle is wustite. Henceforth, the reaction kinetics is governed by a single reaction, wustite $\rightarrow \mathrm{Fe}$ conversion. Ideally, this shift takes place at the transition point. Note that this hypothesis is applicable for reactive particles with magnetite as the only iron oxide phase at the beginning of the reduction reaction, which is consistent with the assumptions discussed in section 5.2.1.

\subsection{Reaction mechanisms governing $f(x)$}

Reaction mechanisms for solid state chemical reactions have been extensively studied and several models were reported. Go et al. [27] divided important reaction mechanisms into three categories; diffusion controlled, boundary controlled and random nucleation. As mentioned earlier, experimentally measured rate of reaction for reduction shows an abrupt change in the slope at the transition point. It is speculated that there is likely a shift in the reaction mechanism for both reactions at the transition point. The iron oxide particle can be approximated as spherical in shape. It is proposed that both reactions, magnetite $\rightarrow$ wustite and wustite $\rightarrow \mathrm{Fe}$ conversions follow a contracting sphere reaction mechanism until the transition point. After the transition point, the reaction mechanism for magnetite $\rightarrow$ wustite conversion transitions into unimolecular decay, and the reaction mechanism for wustite $\rightarrow$ iron conversion transitions into a contracting cylinder mechanism. Ideally, after the transition point, no magnetite is available for reduction, and only wustite $\rightarrow \mathrm{Fe}$ conversion exists within a reactive substrate. However, this hypothesis is based on the microscopic distribution of iron oxide phases in an ideal particle. In reality, morphology of reactive particles in an iron-silica MSPS is highly complex. Thus, after the transition point, some amount of magnetite is likely present in the reactive particles and magnetite $\rightarrow$ wustite conversion is possible. A detailed 
explanation is provided in section 5.6.3. Here it is acknowledged that this is an attempt to interpret highly complex chemical reactions using simplistic and idealized models. The goodness of fit to the experimental data was used as a criterion for choosing the appropriate solid state reaction models. Tables $2 \mathrm{~A} \& 2 \mathrm{~B}$ list the proposed reaction models before and after the transition point, respectively.

Table 2. Proposed reaction mechanisms for chemical reduction, (A) before the transition point, (B) after the transition point.

(A)

\begin{tabular}{|l|l|}
\hline Chemical Reaction & $\mathrm{f}(\mathrm{x})$ \\
\hline Magnetite $\rightarrow$ wustite & $(1-\mathrm{x})^{2 / 3}$ (contracting sphere) \\
\hline Wustite $\rightarrow \mathrm{Fe}$ & $(1-\mathrm{x})^{2 / 3}$ (contracting sphere) \\
\hline
\end{tabular}

(B)

\begin{tabular}{|l|l|}
\hline Chemical Reaction & $\mathrm{f}(\mathrm{x})$ \\
\hline Magnetite $\rightarrow$ wustite & $(1-\mathrm{x})$ (Unimolecular decay) \\
\hline Wustite $\rightarrow \mathrm{Fe}$ & $(1-\mathrm{x})^{1 / 2}$ (contracting cylinder) \\
\hline
\end{tabular}

\subsection{Numerical Scheme}

The species transport equation is a first order PDE in time and space. The equation is solved by an explicit finite difference scheme, forward in time and upwind in space. The bed is discretized into 40 cells $(\mathrm{N}=40)$ and each time step is $0.01 \mathrm{~s}$. A sufficiently small time step is chosen in order to avoid any instability due to the use of the explicit method. The substrate conservation equation is a first order ODE in time and is solved by an explicit method.

Species concentration and fractional conversion of the reactive substrate are solved for all the cells at each time step. The steam concentration in the $\mathrm{N}^{\text {th }}$ cell represents the cumulative generation of steam due to hydrogen reduction within ironsilica MSPS. It is transformed into a rate of steam generation $(\mathrm{g} / \mathrm{min})$ for comparison with experimental measurements. The boundary and initial conditions for species concentration and fractional conversion of the reactive substrate are described. The reactive bed inlet $(z=0)$ always receives hydrogen with the maximum inlet molar concentration,

$$
C_{1}(t, z=0)=C_{o}
$$


At the bed inlet $(z=0)$, only hydrogen is present since no reaction takes place prior to flow through the bed,

$$
C_{2}(t, z=0)=0.0
$$

Since no reaction occurs prior to flowing gas through the reactor at $t=0$,

$$
\begin{aligned}
& C_{1}(t=0, z)=0.0 \\
& C_{2}(t=0, z)=0.0
\end{aligned}
$$

At the start of the reaction, $t=0$ no magnetite or wustite has been converted,

$$
\begin{aligned}
& x_{1}(t=0, \mathrm{z})=0.0 \\
& x_{2}(t=0, \mathrm{z})=0.0
\end{aligned}
$$

\subsection{Computing the fractional conversion of reactive substrate, $x_{i}$}

Fractional conversion of magnetite $x_{1}(t, z)$ is defined as,

$$
x_{1}(t, z)=\frac{\text { Mass of magnetite reduced to wustite }(\mathrm{t}, \mathrm{z})}{\text { Initial mass of magnetite }(\mathrm{z})}
$$

$x_{1}$ is a function of bed length $z$; thus it must be determined in each cell at every time step. The initial mass of magnetite in each computational cell is necessary to evaluate $x_{1}$. The macroscopic distribution, defined in terms of apparent density of magnetite in the structure, provides the necessary framework to evaluate the mass of magnetite at the beginning of the reduction step. Thus, for any control volume bounded by $\eta_{1} \& \eta_{2}$, the initial mass of magnetite can be computed as:

$$
\left(m_{1}\right)_{C V}=\left(\int_{\eta_{1}}^{\eta_{2}} \rho d \eta\right) * m_{\text {max }}
$$

The computed value of the initial mass of magnetite is substituted into the substrate conservation equation to determine $x_{1}$.

The macroscopic distribution of the iron oxide phases assumes a single oxide phase, magnetite, at the beginning of the reduction step, and the initial mass of wustite is zero. Thus, unlike magnetite, the total mass of wustite participating in reduction 
reaction is not available at the beginning of the reduction step. It is generated during magnetite $\rightarrow$ wustite conversion and consumed in wustite $\rightarrow \mathrm{Fe}$ conversion. The fractional conversion of wustite is computed as,

$$
x_{2}(t, z)=\frac{\text { Mass of wustite reduced to iron }(\mathrm{t}, \mathrm{z})}{\text { Available mass of wustite }(\mathrm{t}, \mathrm{z})}
$$

To accommodate this dynamic nature of wustite, the numerical scheme tracks the mass of wustite at each time step in each computational cell. The history of the generation and consumption of wustite from the beginning of the reduction reaction is recorded, and the mass of wustite available for the wustite $\rightarrow$ iron conversion is calculated. Once the available mass of wustite is determined, fractional conversion of wustite, $x_{2}$ is determined from the substrate conservation equation.

\subsection{Using measured reaction rates and the kinetic model to determine kinetic parameters}

A comparison between the kinetic model predictions and experimental measurements of the steam production rate for different operating conditions facilitates determination of the kinetic parameters, including activation energy $\left(E_{a}\right)$, pre-exponent $\left(k_{o}\right)$ and order of reaction $(n)$. The experimental measurements at different reaction temperatures are used to determine the activation energy and pre-exponent, whereas experimental measurements at different hydrogen inlet molar concentrations are used to determine the order of reaction. These kinetic parameters are fundamental for characterizing a chemical reaction, and they must be consistent for all operating conditions. An iterative method is adopted to determine these kinetic parameters by calibrating the kinetic model with experimental measurements. All kinetic parameters are calibrated simultaneously to achieve a good agreement between the kinetic model predictions and experimental measurements for all operating conditions. The criterion for a good agreement is discussed in section 5.6.4.

\subsubsection{Activation energy and pre-exponent}

With an assumed Arrhenius behavior as given in the rate expression, Eq. (4), the rate constant for the chemical reaction is given as

$$
A=k_{o} \operatorname{Exp}(-E a / R T)
$$

The experimental measurements cannot explicitly provide a rate constant value, and an iterative method is adopted to determine the rate constant for both, magnetite $\rightarrow$ wustite and wustite $\rightarrow \mathrm{Fe}$, conversions. The value of the rate constant is varied in each iteration until good agreement (see section 5.6.4) between the kinetic model prediction and the experimental measurement is achieved. The proposed kinetic model is calibrated with experimental measurements at different reaction temperatures. Simultaneous reactions 
of magnetite $\rightarrow$ wustite and wustite $\rightarrow \mathrm{Fe}$ are considered. The natural log of the rate constant, $\ln (A)$, and inverse of the corresponding reaction temperature,1/T are plotted so that a linear relation emerges where the slope reveals the activation energy $\left(E_{a}\right)$ and the intercept reveals the pre-exponent $\left(k_{o}\right)$,

$$
\ln (A)=\ln \left(k_{o}\right)-\frac{E_{a}}{R}\left(\frac{1}{T}\right)
$$

The results for the two reactions are shown in Figures 6 and 7.

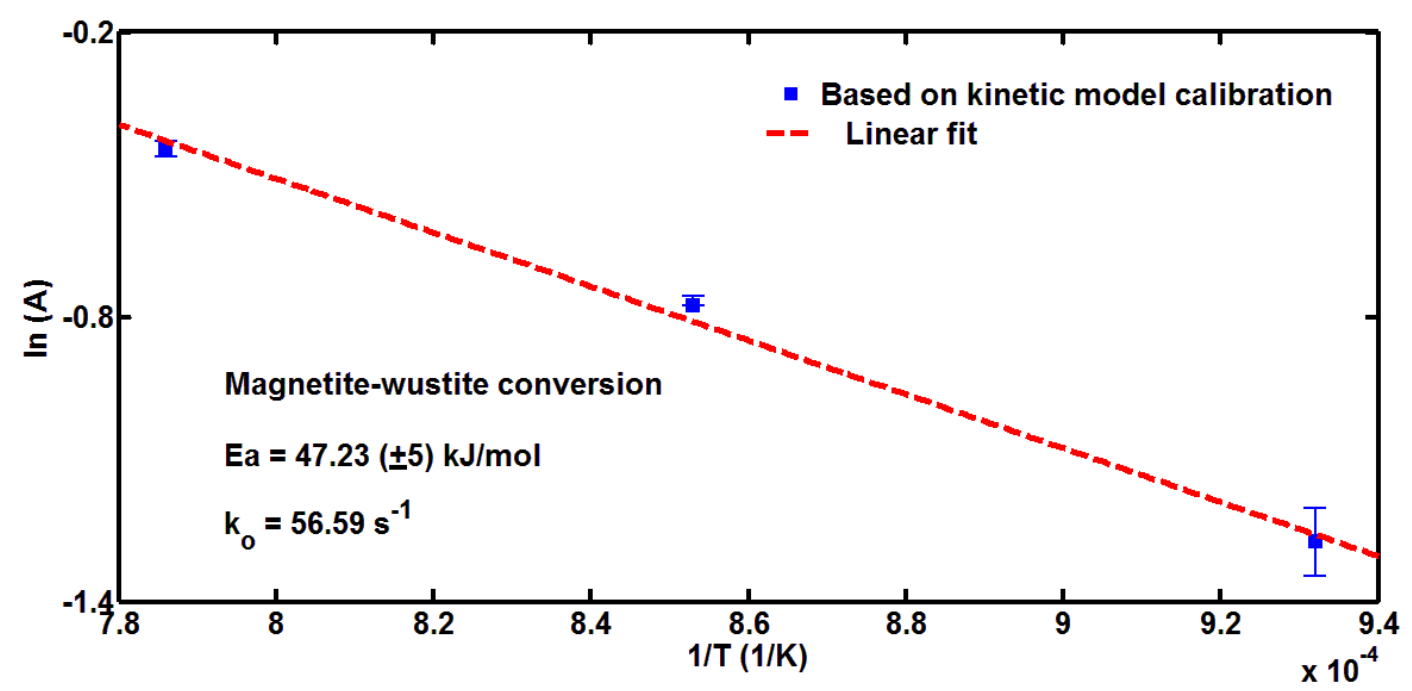

Figure 6. Evaluation of activation energy and pre-exponent for magnetite $\rightarrow$ wustite conversion.

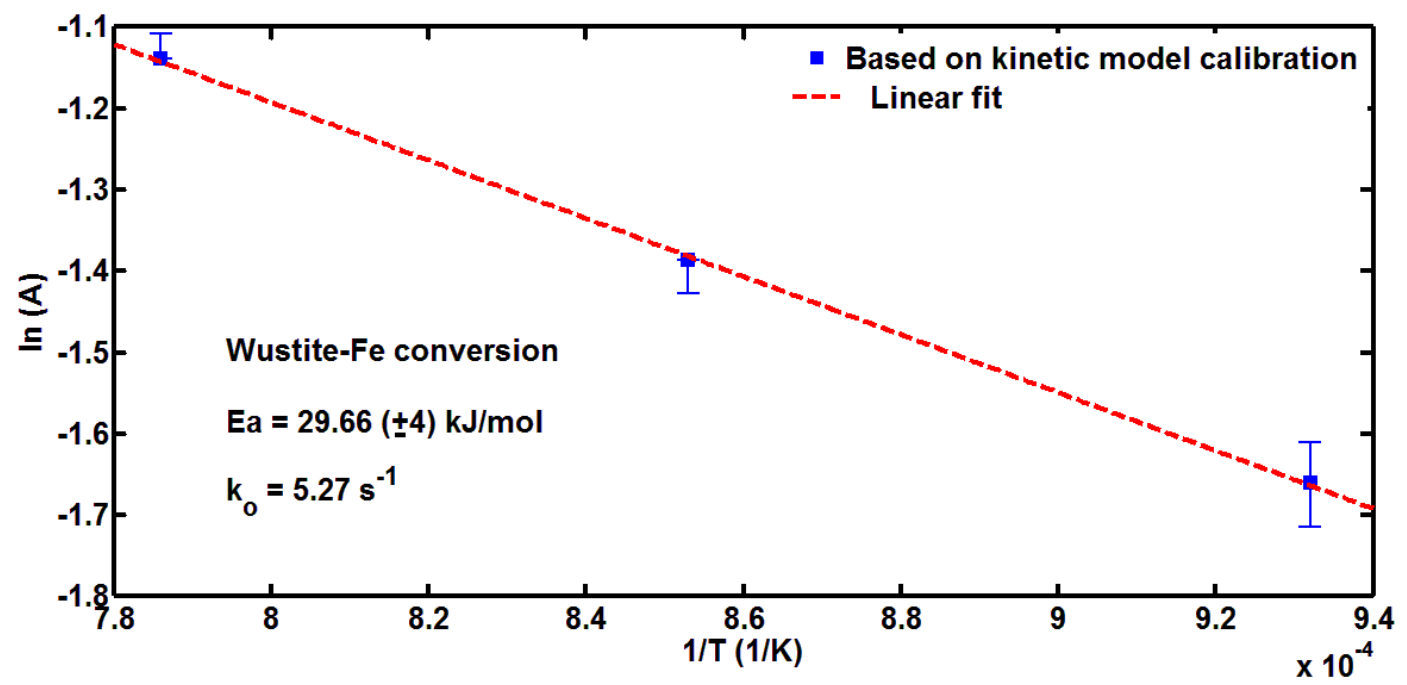

Figure 7. Evaluation of activation energy and pre-exponent for wustite $\rightarrow$ iron conversion 
Table 3. Comparison of activation energy from present work with those reported in the literature.

\begin{tabular}{|c|c|c|c|c|c|}
\hline Author & $\begin{array}{l}\text { Reduction } \\
\text { reaction }\end{array}$ & $\begin{array}{c}E_{a} \\
(\mathrm{~kJ} / \mathrm{mol})\end{array}$ & $\begin{array}{c}\text { Reaction } \\
\text { mechanism }\end{array}$ & $\begin{array}{c}\text { Temperature } \\
\left({ }^{\circ} \mathrm{C}\right)\end{array}$ & $\begin{array}{c}\text { Relevant } \\
\text { operating } \\
\text { conditions }\end{array}$ \\
\hline \multirow[t]{2}{*}{$\begin{array}{l}\text { Present } \\
\text { work }\end{array}$} & $\mathrm{Fe}_{3} \mathrm{O}_{4} \rightarrow \mathrm{FeO}$ & 47 & $\begin{array}{l}\text { Phase boundary } \\
\text { controlled }\end{array}$ & $\begin{array}{l}800-1000 \\
\text { Isothermal }\end{array}$ & Pure $\mathrm{H}_{2}$ \\
\hline & $\mathrm{FeO} \rightarrow \mathrm{Fe}$ & 30 & $\begin{array}{l}\text { Phase boundary } \\
\text { controlled }\end{array}$ & $\begin{array}{l}800-1000 \\
\text { Isothermal }\end{array}$ & Pure $\mathrm{H}_{2}$ \\
\hline \multirow[t]{3}{*}{$\begin{array}{l}\text { Pineau et } \\
\text { al. [5] }\end{array}$} & $\mathrm{Fe}_{3} \mathrm{O}_{4} \rightarrow \mathrm{Fe}$ & 39 & $\begin{array}{l}\text { Phase boundary } \\
\text { controlled }\end{array}$ & $\begin{array}{l}\mathrm{T}>417 \\
\text { Isothermal }\end{array}$ & Pure $\mathrm{H}_{2}$ \\
\hline & $\mathrm{Fe}_{3} \mathrm{O}_{4} \rightarrow \mathrm{Fe}$ & 88 & $\begin{array}{l}\text { 2-3D nuclei } \\
\text { growth }\end{array}$ & $\begin{array}{l}\mathrm{T}<417 \\
\text { Isothermal }\end{array}$ & Pure $\mathrm{H}_{2}$ \\
\hline & $\mathrm{Fe}_{3} \mathrm{O}_{4} \rightarrow \mathrm{Fe}$ & 36 & $\begin{array}{l}\text { Phase boundary } \\
\text { controlled }\end{array}$ & $\begin{array}{l}>415 \\
\text { Isothermal }\end{array}$ & $\begin{array}{l}\mathrm{H}_{2}+\mathrm{N}_{2}(10 \% \\
+90 \%)\end{array}$ \\
\hline \multirow[t]{4}{*}{$\begin{array}{l}\text { Pineau et } \\
\text { al. [6] }\end{array}$} & $\mathrm{Fe}_{3} \mathrm{O}_{4} \rightarrow \mathrm{Fe}$ & 200 & $\begin{array}{l}\text { Phase boundary } \\
\text { controlled }\end{array}$ & $\begin{array}{l}227-250 \\
\text { Isothermal }\end{array}$ & $\begin{array}{l}\text { Pure } \mathrm{H}_{2}, \\
\left(\mathrm{Fe}_{3} \mathrm{O}_{4}\right)_{600}{ }^{\circ} \mathrm{C}\end{array}$ \\
\hline & $\mathrm{Fe}_{3} \mathrm{O}_{4} \rightarrow \mathrm{Fe}$ & 71 & $\begin{array}{l}\text { Phase boundary } \\
\text { controlled }\end{array}$ & $\begin{array}{l}250-390 \\
\text { Isothermal }\end{array}$ & $\begin{array}{l}\text { Pure } \mathrm{H}_{2}, \\
\left(\mathrm{Fe}_{3} \mathrm{O}_{4}\right)_{600}{ }^{\circ} \mathrm{C}\end{array}$ \\
\hline & $\mathrm{Fe}_{3} \mathrm{O}_{4} \rightarrow \mathrm{Fe}$ & 44 & $\begin{array}{l}\text { 2D growth of } \\
\text { nuclei }\end{array}$ & $\begin{array}{l}>390 \\
\text { Isothermal }\end{array}$ & $\begin{array}{l}\text { Pure } \mathrm{H}_{2}, \\
\left(\mathrm{Fe}_{3} \mathrm{O}_{4}\right)_{600}{ }^{\circ} \mathrm{C}\end{array}$ \\
\hline & $\mathrm{Fe}_{3} \mathrm{O}_{4} \rightarrow \mathrm{Fe}$ & 80 & $\begin{array}{l}\text { Phase boundary } \\
\text { controlled }\end{array}$ & $\begin{array}{l}220-390 \\
\text { Isothermal }\end{array}$ & $\begin{array}{l}\text { Pure } \mathrm{H}_{2}, \\
\left(\mathrm{Fe}_{3} \mathrm{O}_{4}\right)_{1200}{ }^{\circ} \mathrm{C}\end{array}$ \\
\hline $\begin{array}{l}\text { Lin et al. } \\
{[7]}\end{array}$ & $\mathrm{Fe}_{3} \mathrm{O}_{4} \rightarrow \mathrm{Fe}$ & 70 & Avarmi-Erofeev & $\begin{array}{l}25-900 \\
\text { TPR }\end{array}$ & $\begin{array}{l}\mathrm{H}_{2}+\mathrm{N}_{2}(5 \% \\
+95 \%)\end{array}$ \\
\hline \multirow[t]{2}{*}{$\begin{array}{l}\text { Tiernan } \\
\text { et al. [14] }\end{array}$} & $\mathrm{Fe}_{3} \mathrm{O}_{4} \rightarrow \mathrm{Fe}$ & $59-69$ & $\begin{array}{l}\text { Random } \\
\text { nucleation }\end{array}$ & $\begin{array}{l}\text { 245-295 } \\
\text { CRTA }\end{array}$ & $\begin{array}{l}5 \% \mathrm{H}_{2} \text { in } \mathrm{He} \\
\text { Starting } \\
\text { material- } \\
\mathrm{Fe}_{2} \mathrm{O}_{3}\end{array}$ \\
\hline & $\mathrm{Fe}_{3} \mathrm{O}_{4} \rightarrow \mathrm{Fe}$ & $61-75$ & NA & $\begin{array}{l}260-345 \\
\text { CRTA }\end{array}$ & $\begin{array}{l}5 \% \mathrm{H}_{2} \text { in } \mathrm{He} \\
\text { Starting } \\
\text { material- } \\
\mathrm{Fe}_{3} \mathrm{O}_{4}\end{array}$ \\
\hline $\begin{array}{l}\text { Jung and } \\
\text { Lee [28] }\end{array}$ & $\mathrm{Fe}_{2} \mathrm{O}_{3} \rightarrow \mathrm{Fe}$ & $35-46$ & $\mathrm{NA}$ & $\begin{array}{l}250-750 \\
\text { Linear heating }\end{array}$ & Pure $\mathrm{H}_{2}$ \\
\hline \multirow[t]{3}{*}{$\begin{array}{l}\text { Jozwiak } \\
\text { et al. [29] }\end{array}$} & $\mathrm{Fe}_{3} \mathrm{O}_{4} \rightarrow \mathrm{Fe}$ & 52 & NA & $\begin{array}{l}25-1000 \\
\text { TPR }\end{array}$ & Pure $\mathrm{H}_{2}$ \\
\hline & $\mathrm{Fe}_{3} \mathrm{O}_{4} \rightarrow \mathrm{Fe}$ & 55 & NA & $\begin{array}{l}25-1000 \\
\text { TPR }\end{array}$ & Pure $\mathrm{H}_{2}$ \\
\hline & $\mathrm{FeO} \rightarrow \mathrm{Fe}$ & 104 & NA & $\begin{array}{l}25-1000 \\
\text { TPR }\end{array}$ & Pure $\mathrm{H}_{2}$ \\
\hline
\end{tabular}


The activation energy of a chemical reaction is significantly influenced by various parameters including reaction temperature, particle size, structural characteristics of the reactive substrate, and the method of synthesis. The measured activation energy for iron oxide reduction reported in the literature shows significant variation. A review of previous studies by Pineau et al. [6] revealed that the activation energy of magnetite $\rightarrow \mathrm{Fe}$ conversion varies in the range $13-167 \mathrm{~kJ} / \mathrm{mol}$. Table 3 compares select activation energies reported in the literature with those determined as part of the current investigation. Probable reasons for variation in the activation energy for iron oxide reduction are discussed in brief.

Pineau et al. [5] studied step-wise reduction of hematite to iron, and reported an abrupt decrease in the activation energy for magnetite $\rightarrow \mathrm{Fe}$ conversion at $417^{\circ} \mathrm{C}$, denoted as the transition temperature, $T_{t}$ (see Table 3 ). They proposed that, for $T_{>} T_{t}$, the wustite phase is present in the reactive substrate and that may influence the reaction kinetics causing a decrease in the activation energy. Jung and Lee [28] studied the reduction of hematite nanoparticles for the production of metallic iron. A gradual decrease in the activation energy from 46 to $35 \mathrm{~kJ} / \mathrm{mol}$ was observed as the reduction extent increased from 0.1 to 0.8 . They proposed that a decrease in the activation energy was likely due to the presence of intermediate iron oxide phases during conversion of hematite to iron, $\mathrm{Fe}_{2} \mathrm{O}_{3} \rightarrow \mathrm{Fe}_{3} \mathrm{O}_{4} \rightarrow \mathrm{FeO} \rightarrow \mathrm{Fe}$. Tiernan et al. [14] reported a decrease in activation energy for magnetite $\rightarrow \mathrm{Fe}$ conversion with an increase in the extent of the reduction reaction. These findings suggest that the activation energy for magnetite $\rightarrow$ wustite conversion is higher than for wustite $\rightarrow F e$ conversion, and are in general agreement with the present study. Pineau et al. [6] studied the effect of the structural characterization of reactive material (magnetite) on reduction kinetics of magnetite $\rightarrow \mathrm{Fe}$ conversion. Two samples of magnetite were synthesized by reduction of hematite at $600{ }^{\circ} \mathrm{C}$ and $1200{ }^{\circ} \mathrm{C}$, designated as $\left(\mathrm{Fe}_{3} \mathrm{O}_{4}\right) 600^{\circ} \mathrm{C}$ and $\left(\mathrm{Fe}_{3} \mathrm{O}_{4}\right) 1200{ }^{\circ} \mathrm{C}$, respectively. The reduction rate for both samples was comparable in the temperature range, $250-600{ }^{\circ} \mathrm{C}$. However, the activation energy for $\left(\mathrm{Fe}_{3} \mathrm{O}_{4}\right) 600^{\circ} \mathrm{C}$ reduction showed an abrupt change at $250{ }^{\circ} \mathrm{C}$, which was not observed during reduction of $\left(\mathrm{Fe}_{3} \mathrm{O}_{4}\right) 1200^{\circ} \mathrm{C}$. The authors concluded that, the difference in behavior is likely due to variations in the structural characteristics of the two sample of magnetite synthesized at different temperatures. Tiernan et al. [14] investigated iron oxide reduction with magnetite and hematite as starting iron oxides. They reported different activation energies for magnetite $\rightarrow \mathrm{Fe}$ conversion; when starting iron oxide is switched from hematite to magnetite, and the difference was attributed to the variation in the textural characteristics of the two starting materials. Many researchers have studied iron oxide reduction for non-isothermal conditions. Lin et al. [7] determined the activation energy for hematite reduction in the temperature range of $25-900^{\circ} \mathrm{C}$ using TPR (temperature programmed reduction) method. Tiernan et al. [14] used CRTA (constant rate thermal analysis) and TPR techniques to study iron oxide reduction up to $700^{\circ} \mathrm{C}$. Jozwiak et al. 
[29] studied reduction of hematite, magnetite, and wustite using TPR method in the temperature range of $25-1000^{\circ} \mathrm{C}$. In these studies, temperatures used to determine activation energy were in the range $250-650^{\circ} \mathrm{C}$. Activation energies reported in these studies are higher than activation energies reported in the present work. It is likely that, presence of wustite at higher reduction temperatures, $800-1000^{\circ} \mathrm{C}$ for the present work, resulted in lower activation energy as discussed earlier in this section. Note that, activation energy for $\mathrm{FeO} \rightarrow \mathrm{Fe}$ reduction, reported by Jozwiak et al. [29], was for the wustite as a starting material and not as an intermediate iron oxide phase. In addition, iron-silica MSPS is a highly reactive porous structure that provides greater surface area for the chemical reactions. Thus favorable structural characteristics of iron silica MSPS are likely to lower the activation energy for iron oxide reduction. Activation energy values and reaction mechanisms determined in this study are in agreement with those of Pineau et al. [5, 6], and Jung and Lee [28]. This discussion provides valuable insight into the influence of various parameters on the activation energy, and underscores the need for careful examination of operating conditions used for iron oxide reduction.

\subsubsection{Order of Reaction}

The order of reaction, $n$ determines the influence of species molar concentration on the rate of reaction. Experimental measurements of the peak rate of reaction can be used for an initial estimate of the reaction order. Once the initial estimate is made, the reaction order can be further refined through tuning the kinetic model with experimental data. The peak rate of reaction was observed at the very beginning of the reduction step. At the start of the reaction, the molar concentration of hydrogen in the reactor is the hydrogen inlet molar concentration, $C_{0}$. Thus for an isothermal reactor, the peak rate of reaction can be expressed as

$$
\ln \left(\dot{r}_{\text {peak }}\right)=\text { constant }+n \ln \left(C_{o}\right)
$$

Figure 8 shows the natural log of the peak reaction rate, $\ln \dot{r}_{\text {peak }}$, as a function of the natural $\log$ of the hydrogen inlet molar concentration, $\ln C_{o}$. This initial estimate suggests that the reaction order is unity. The kinetic model is used to tune this initial estimate for different experimental measurements. The order of reaction did not show any significant deviation from unity (ranges from 0.95 to 1.2) for different operating conditions, which confirms the initial estimate within experimental uncertainty. For practical purpose, the order of reaction was chosen to be unity for different operating conditions without any significant loss of accuracy. 


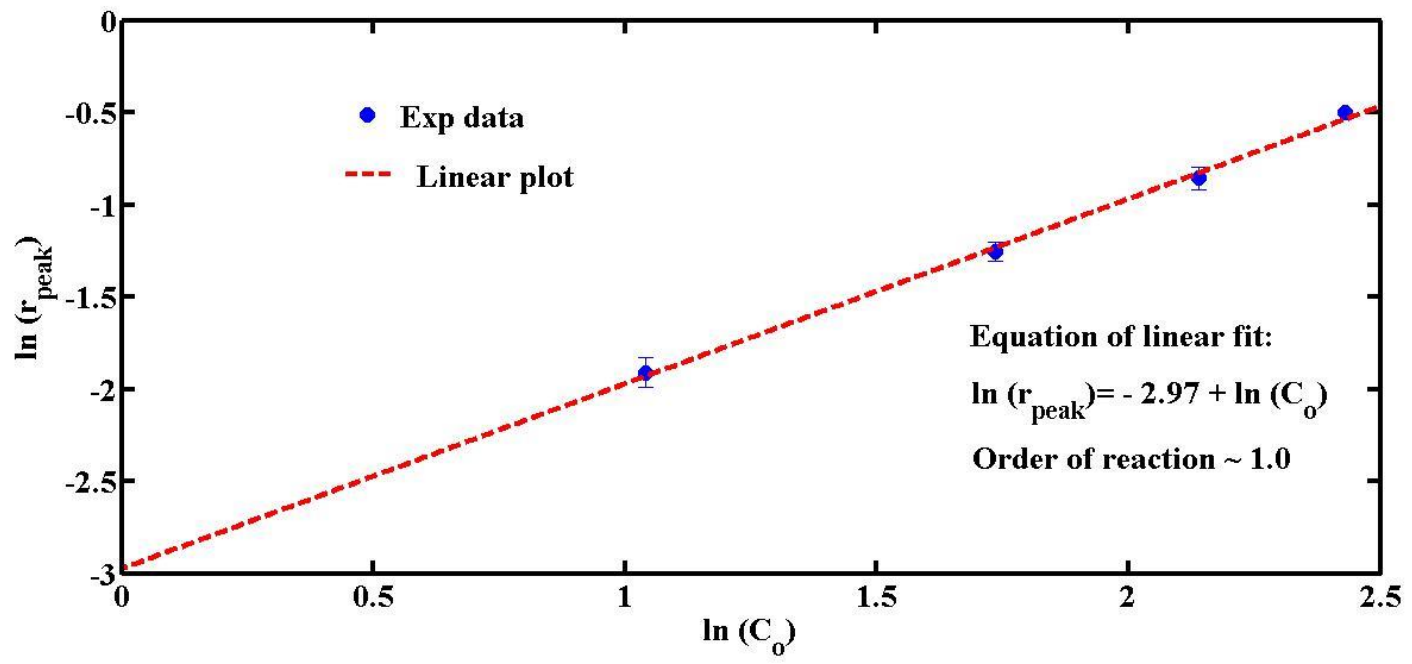

Figure 8. Estimation of the reaction order using the peak reaction rate.

\subsubsection{Transition point}

The transition point is characterized by the transition in chemical reactions and reaction mechanisms. The transition point is defined as the time at which complete conversion of magnetite to wustite occurs; the transition point is identified by a sudden change in the slope of the reaction rate. $x_{1}$ (fractional conversion of magnetite) was tracked to determine the transition point for different operating conditions. Ideally, $x_{1}=1$ at the transition point, but this was not observed. A kinetic model was used to investigate the value of $x_{1}$ at the transition point; it was found that $x_{1}=0.8$ at the transition point for the experimental conditions considered. The reason for $x_{1}$ less than unity at the transition point can be explained based on the following phenomena.

\subsubsection{Morphology of the reactive material in iron-silica MSPS}

An ideal particle assumes a spherical shape with a well-defined distribution of the oxide phases, magnetite and wustite, at the end of the oxidation step, as shown in Figure 5. When an ideal particle is subjected to the reduction step, the reaction front, approaching from the periphery of the particle, reaches the interface between the oxide phases, simultaneously from all directions, and when the transition point is reached, magnetite is completely reduced, $x_{1}=1$. In reality, reactive particles do not have welldefined spherical morphology at the microscopic level. Moreover, in an iron-silica MSPS, iron particles sinter in a systematic manner to form chains in the direction of a magnetic field (Fig. 3, Ref. 1). Thus the morphology of the reactive material in an ironsilica MSPS is too complex to be defined by ideal geometries. In such structures, it is unlikely to have a well-defined distribution of the oxide phases separated by a 
prominent interface. When such a structure is subjected to the reduction reaction, the reaction front may not reach the interface simultaneously from all directions, and it is likely that some amount of magnetite is not reduced to wustite, and the value of $x_{1}$ at the transition point is less than unity.

\subsubsection{Dynamic nature of reduction reactions in iron-silica MSPS}

It is acknowledged that the rate of reduction is cumulative effect of two reduction reactions, magnetite $\rightarrow$ wustite and wustite $\rightarrow \mathrm{Fe}$. As the reduction reaction proceeds, the mass of magnetite available for the reaction decreases; thus the influence of magnetite $\rightarrow$ wustite conversion on the rate of reduction decreases and that of wustite $\rightarrow \mathrm{Fe}$ conversion increases. It is likely that, at transition point, $x_{1}=0.8$, the mass of magnetite reaches a threshold limit below which, magnetite $\rightarrow$ wustite conversion has no decisive influence on the rate of reaction. Henceforth, wustite $\rightarrow \mathrm{Fe}$ conversion drives the reduction reaction with a secondary contribution from magnetite $\rightarrow$ wustite conversion until the mass of magnetite is completely exhausted.

\subsubsection{Criterion for a good agreement between kinetic model predictions and experimental measurements}

All empirically determined kinetic parameters are summarized in Table 4. Since the kinetic parameters are tuned to achieve good agreement between the proposed kinetic model and experimental measurements, it is important to discuss a criterion to define a 'good fit'. For every iteration, an absolute difference between experimental measurement and kinetic model prediction of the reaction rate is computed in each time step and its statistical mean is calculated to determine an average error. Accuracy of the experimental measurements of rate of steam generation is primarily dictated by the accuracy of the flow measuring device (Alicat MC 20 SLPM flowmeter). Based on technical specifications of this flow meter, accuracy of the experimental steam generation rate measurements is computed to be $\pm 0.035 \mathrm{~g} / \mathrm{min}$. This value is taken as a maximum acceptable threshold average error, below which, the kinetic model predictions are said to have a good agreement with the experimental measurements. Moreover, it is of interest to analyze the distribution of absolute error; thus the standard deviation of absolute error is determined. Table 5 lists the average error and standard deviation of the absolute error for the reduction step for all the cycles listed in Table 1. 
Table 4. Summary of empirically determined kinetic parameters for proposed reduction reactions.

\begin{tabular}{|c|c|c|}
\hline Kinetic parameter & $\begin{array}{c}\text { Magnetite- } \\
\text { wustite }\end{array}$ & Wustite-Fe \\
\hline Activation energy $(\mathrm{kJ} / \mathrm{mol})$ & 47.23 & 29.66 \\
\hline Pre-exponent $(1 / \mathrm{s})$ & 56.59 & 5.27 \\
\hline Order of reaction & 1.0 & 1.0 \\
\hline Transition point $\left(\mathrm{X}_{1}\right)$ & 0.8 & 0.8 \\
\hline
\end{tabular}

Table 5. Average error and standard deviation of error for the best fit of the kinetic model to the experimental rate measurements for all operating conditions.

\begin{tabular}{|c|c|c|}
\hline $\begin{array}{c}\text { Cycle } \\
\text { No. }\end{array}$ & $\begin{array}{c}\text { Mean error } \\
(\mathrm{g} / \mathrm{min})\end{array}$ & $\begin{array}{c}\text { Standard deviation } \\
(\mathrm{g} / \mathrm{min})\end{array}$ \\
\hline 1 & 0.0268 & 0.0123 \\
\hline 2 & 0.0222 & 0.0088 \\
\hline 3 & 0.014 & 0.0082 \\
\hline 4 & 0.0191 & 0.0092 \\
\hline 5 & 0.0138 & 0.005 \\
\hline 6 & 0.0097 & 0.0089 \\
\hline 7 & 0.0219 & 0.016 \\
\hline
\end{tabular}

Figures 9 to 11 show a comparison between experimental measurements of steam production rate and those predicted using the proposed calibrated kinetic model for different operating conditions. 


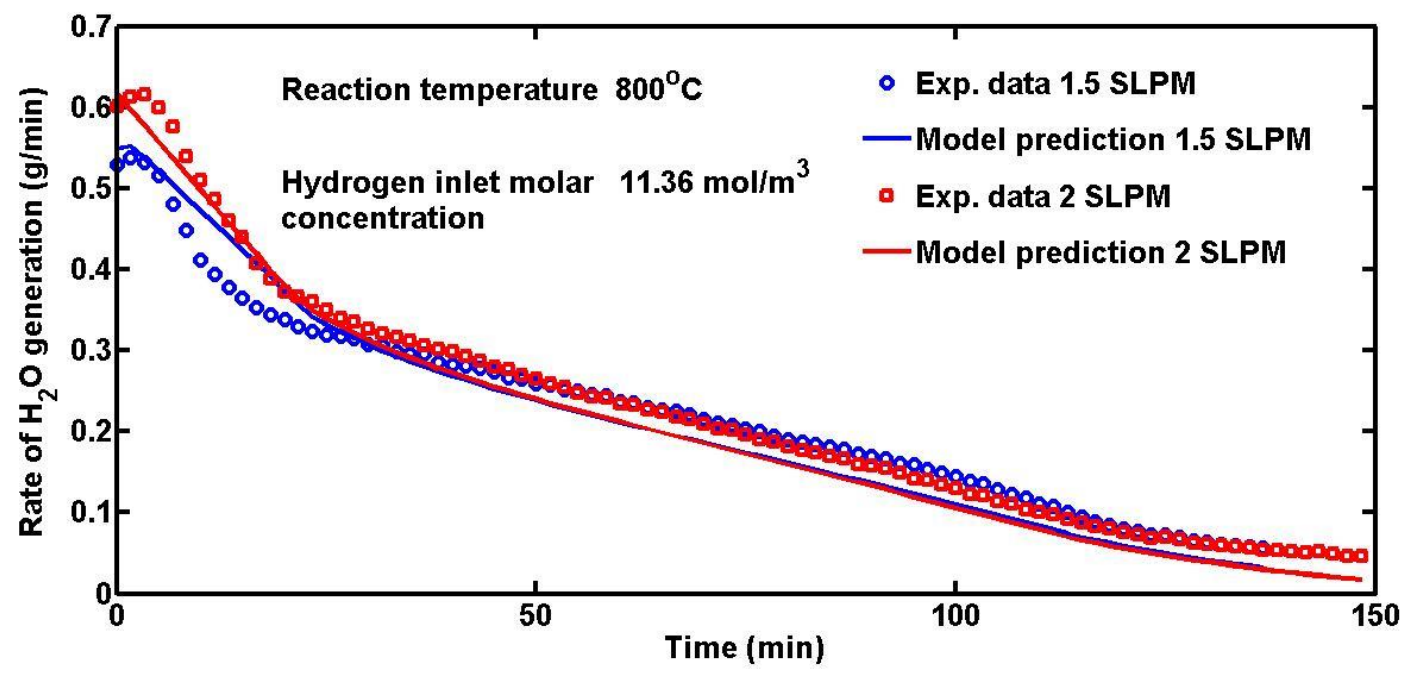

Figure 9. Comparison between measured and predicted steam production rate for various hydrogen inlet flow rates.

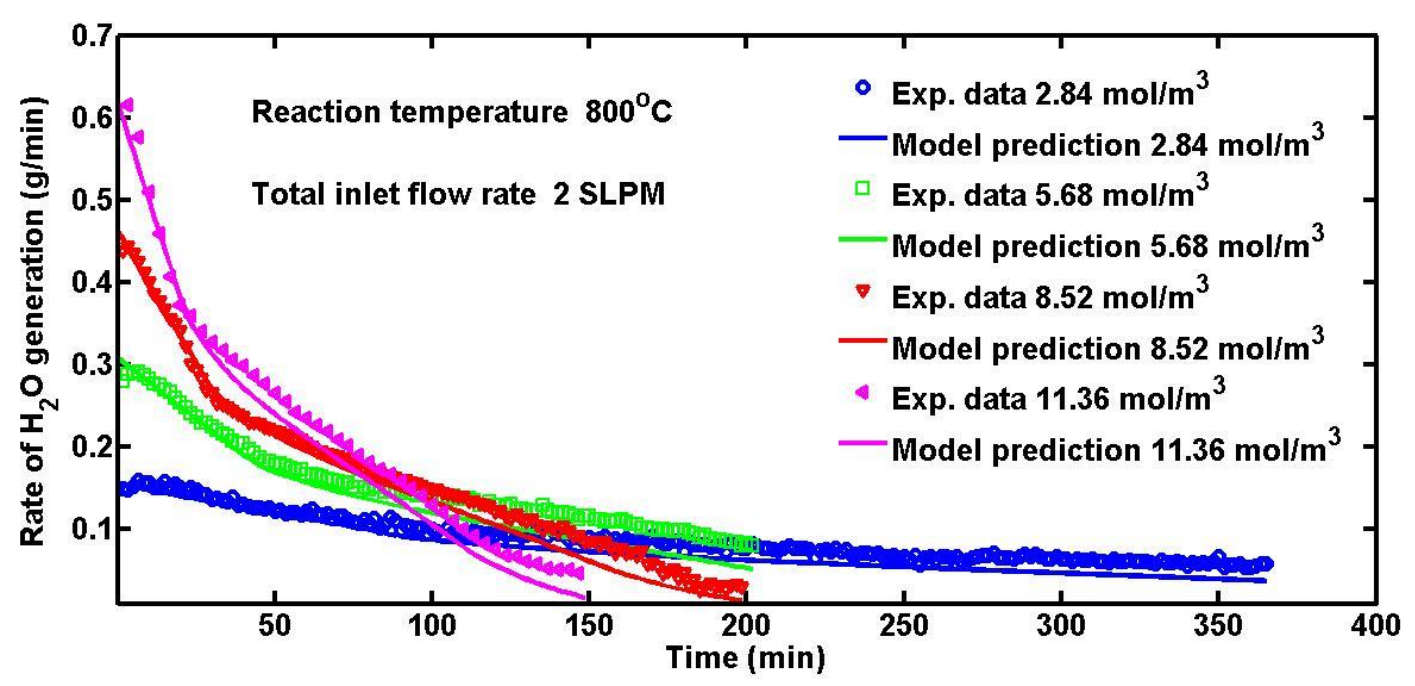

Figure 10. Comparison between measured and computed steam production rate for different hydrogen inlet molar concentration. 


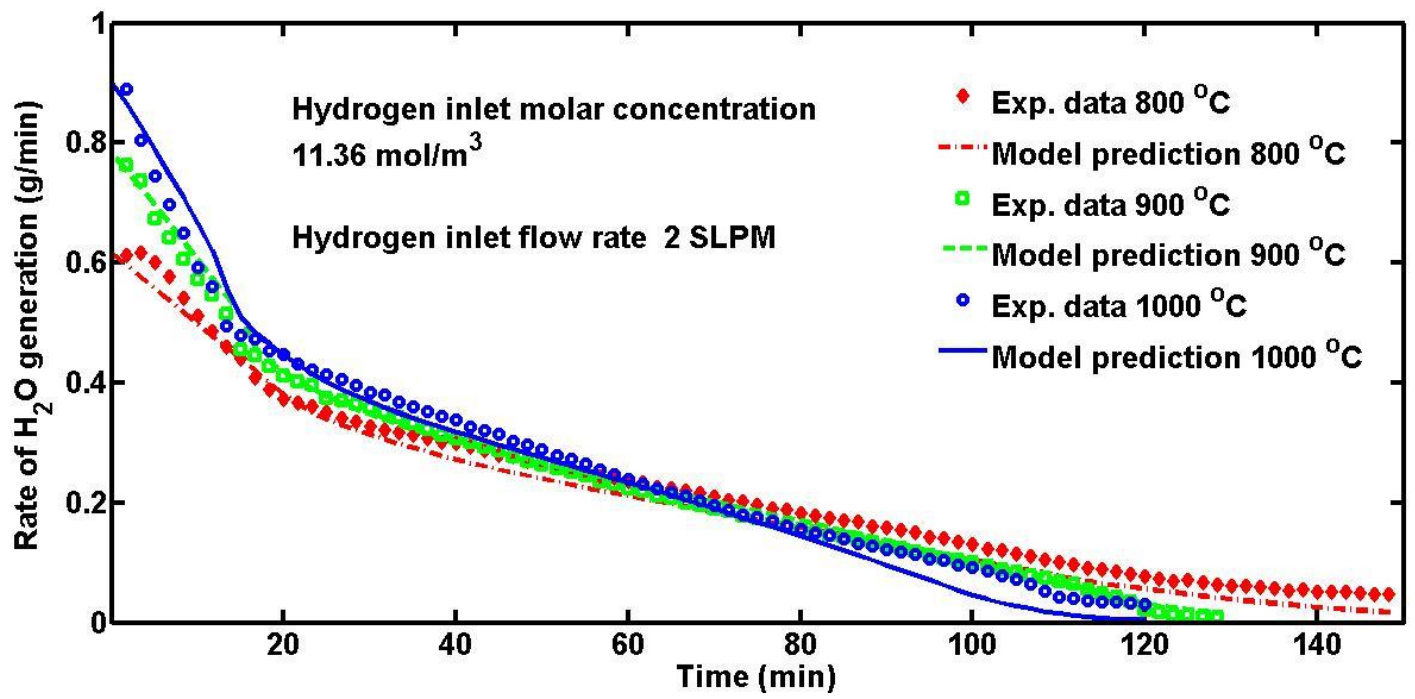

Figure 11. Comparison between measured and computed steam production rate for different reaction temperatures.

\section{Discussion}

A comparison between the measured and predicted steam production rate shows good agreement between the kinetic model and experimental measurements over a limited range of operating conditions. Despite the conjectures and simplifications used to construct the kinetic model, it provides an excellent framework for designing and scaling industrial reactors. However, the utility of the model is not restricted to industrial practice. A highly complex iron oxide reduction process, involving multiple reactions and mechanisms has been sorted out. The parametric study provides essential insight into the nature of the reaction kinetics and underlying physics. It is acknowledged that the kinetic model is speculative in nature, although an attempt has been made to substantiate the assumptions, either by analytical treatment or experimental measurements. None of the assumptions were found to be inconsistent with first principles. There is significant scope for improving on the model, which is discussed next.

\subsection{Reaction mechanism}

The kinetic study of hydrogen reduction indicates that the reaction mechanism includes phase boundary controlled reaction phenomena. According to the kinetic study of steam oxidation in an iron-silica MSPS [2], the oxidation reaction initially follows a contracting sphere reaction mechanism (for $\mathrm{x}<0.3$ ) and then transitions into a diffusion control reaction mechanism (Jander model). Similarly, for hydrogen reduction, it was speculated that the phase boundary reaction mechanism would govern the reduction reaction in its early stages. It was believed that the product layer would serve as a 
barrier for the transport of the reacting species (hydrogen) and a diffusion controlled reaction mechanism was thought to govern the reaction kinetics. Contrary to the diffusion controlled supposition, the current study shows that both reduction reactions follow phase boundary controlled reaction mechanisms throughout the reduction step. Apparently, the product layer formed during the reduction reaction is less likely to pose any significant barrier to the hydrogen transport to the reacting media. This is likely due to the small size and highly diffusive nature of hydrogen molecules.

\subsection{Effect of iron oxide phases and their distribution on reaction kinetics}

The distribution of iron oxide phases in an iron-silica MSPS plays a pivotal role in the reaction kinetics with hydrogen reduction. The mass distribution of the iron oxide phases varies with time and space, and this variation is closely associated with the transition in the chemical reactions and reaction mechanisms. Thus, it is appropriate to acknowledge the impact of the dynamic nature of the iron oxide distribution, at the macro- and microscopic scales.

The macroscopic distribution of the iron oxide phases at the beginning of the reduction step is important for determining the fractional conversion of the reactive substrate $\left(x_{i}\right)$. The analytical treatment proposed in Appendix B provides an excellent tool to estimate the macroscopic distribution in the reactive structure. The necessity for such an analysis is intensified for the design of industrial scale reactors, where spatial gradients in key thermodynamic parameters, including reaction temperature and molar concentration of the reacting species, may induce significant gradients in the distribution of iron oxide phases across the reactive structure. Although this analysis provides a framework for determining the macroscopic distribution of iron oxide phases, there is a scope for improvement. Thermodynamic analysis of the oxidation step indicates the presence of different iron oxide phases at the end of the oxidation step (beginning of the reduction step) $[19,20]$, and a mechanism should be developed to account for them.

The microscopic distribution of iron oxide phases has a controlling influence on the transition of the chemical reactions and reaction mechanisms. A study of the microscopic distribution attempts to provide a comprehensive explanation for the dynamic behavior of the chemical reactions and the reaction mechanisms. A transition from the co-existence of both reduction reactions to the presence of wustite $\rightarrow \mathrm{Fe}$ conversion, is well-described based on the microscopic distribution. Moreover, the microscopic distribution correlates the structural morphology of the reactive structure with the reaction mechanisms. A sketch of the structural morphology of the reactive material and the distribution of iron oxide phases at different stages of the reduction reaction is depicted in Figures 10a-c. 
Cylinder like core

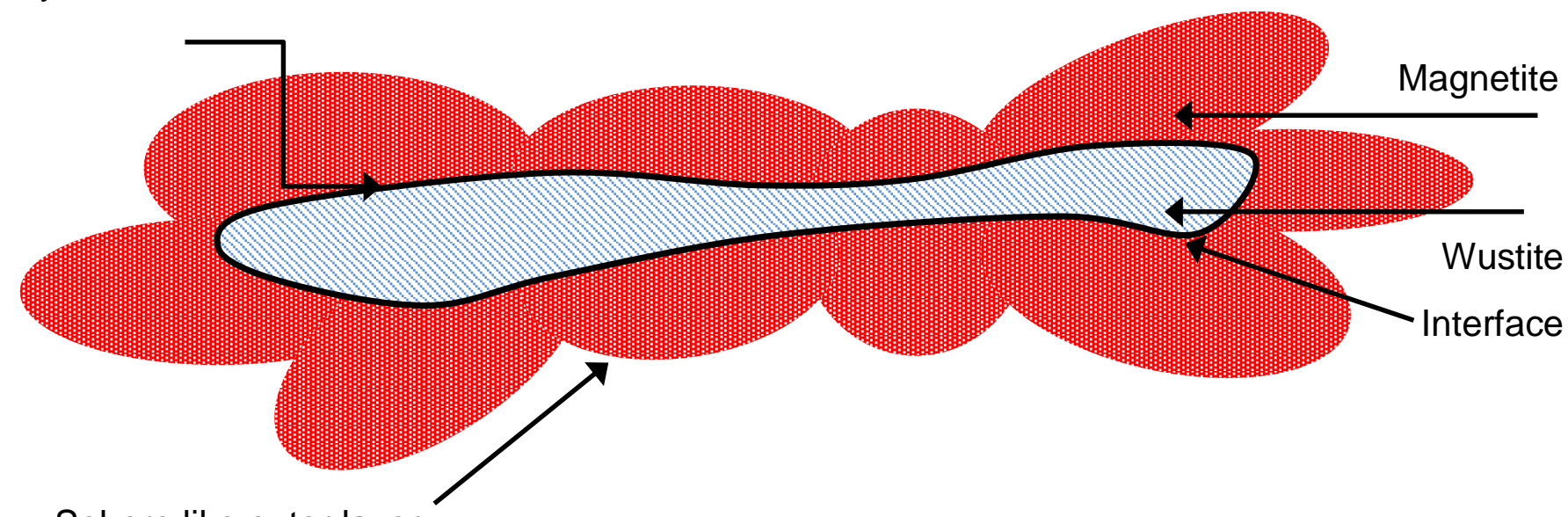

Sphere like outer layer

Figure 10a. Structural morphology and microscopic distribution of iron oxide phases within the MSPS structure at the beginning of the reduction reaction.

The reactive structure is synthesized via systematic sintering of the iron particles aligned in the direction of the magnetic field to form chains (Fig. 3, Ref. 16). In the outer layer of the reactive structure, the local morphology can be described by the spherical geometry, while the core of the reactive structure can be described by the cylindrical geometry. Since the reaction front approaches from the periphery of the reactive structure prior to the transition point, both reduction reactions likely occur in the outer layer, and thus a contracting sphere reaction mechanism is reasonable.

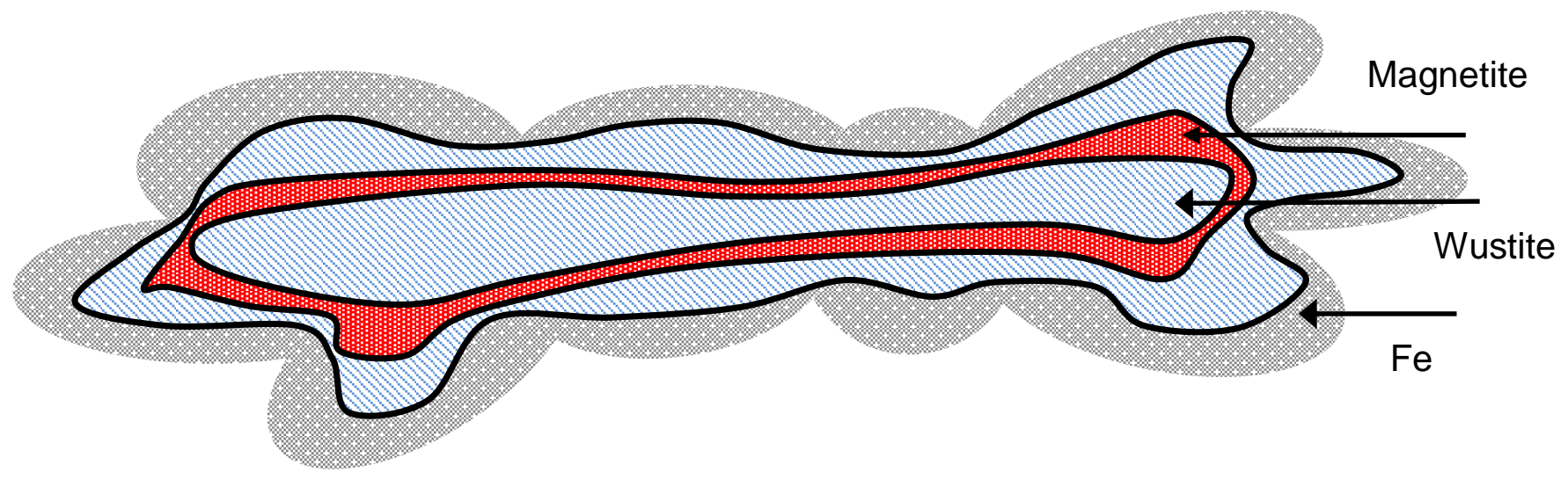

Figure 10b. Structural morphology and microscopic distribution of iron oxide phases within the MSPS structure during the reduction reaction and prior to the transition point.

By the time the transition point is reached, the outer layer is likely converted into elemental iron, and the reduction reaction predominantly occurs at the core of the 
structure. Thus, wustite $\rightarrow \mathrm{Fe}$ conversion in the cylindrical core of the structure may follow a contracting cylinder reaction mechanism. Since a significant mass of magnetite is reduced by the time the transition point is reached $\left(x_{1}=0.8\right)$, the remaining mass of magnetite is likely to be present in the form of thin layers, and the conversion of magnetite to wustite after the transition point follows a unimolecular decay reaction mechanism.

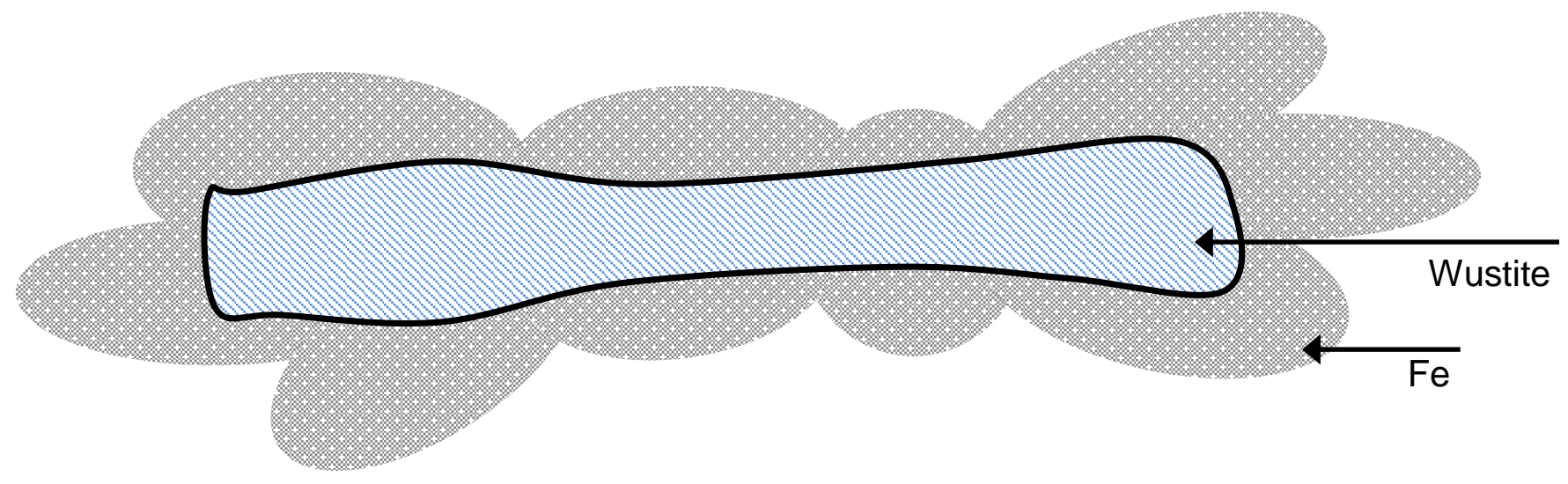

Figure 10c. Structural morphology and microscopic distribution of iron oxide phases within the MSPS structure during the reduction reaction and after the transition point.

This conceptual view of the microscopic iron oxide distribution within the MSPS structure provides an explanation for the reaction mechanisms that were empirically determined and listed in Table 2.

\section{Conclusion}

The reaction kinetics for the solid state reduction of iron oxide in iron-silica magnetically stabilized porous structures is investigated in a laboratory scale reactor. The influences of reaction temperature, hydrogen inlet molar concentration, and hydrogen inlet flow rate are studied experimentally. The reduction of iron oxide is characterized by the presence of two reactions, magnetite $\rightarrow$ wustite and wustite $\rightarrow \mathrm{Fe}$ conversion. A one dimensional plug flow isothermal kinetic model is developed to determine important kinetic parameters, including activation energy, pre-exponent, and order of reaction, for both simultaneous reactions. The role of the macroscopic and microscopic distributions of iron oxides in the reaction kinetics is identified. A sudden change in the slope of the rate of reduction is attributed to a transition in chemical reactions and reaction mechanisms. The key kinetic parameters for magnetite $\rightarrow$ wustite and wustite $\rightarrow$ Fe conversion are: activation energy, $47.23 \mathrm{~kJ} / \mathrm{mol} \& 29.66 \mathrm{~kJ} / \mathrm{mol}$; preexponent, $56.591 / \mathrm{s} \& 5.271 / \mathrm{s}$ respectively; the order of reaction is unity for both 
reactions. A transition point is defined in terms of $x_{1}$ (fractional conversion of magnetite), and empirical analysis is used to determine its value as $x_{1}=0.8$. Good agreement is achieved between the kinetic model predictions and experimental measurements for different operating conditions. The kinetic model is robust and serves as an excellent analytical tool that can be used to design laboratory and industrial reactors.

\section{Acknowledgement}

This paper was prepared with the support of the U.S. Department of Energy under Award No. DE-FE0001321.

\section{References}

1. Mehdizadeh A, Klausner J, Barde A, Rahmatian N, Mei R. Enhancement of thermochemcial hydrogen production Using an iron-silica magnetically stabilized porous structure. Int. J. of Hydrogen Energy 2012; 37:8954-63.

2. Mehdizadeh A, Klausner J, Barde A, Rahmatian N, Mei R. Investigation of hydrogen production reaction kinetics for an iron-silica magnetically stabilized porous structure. I. Journal of Hydrogen Energy 2012; 37:13263-71.

3. Allen K, Mehdizadeh A, Klausner J, Coker E. Study of a Magnetically Stabilized Porous Structure for Thermochemical Water Splitting via TGA, High-

Temperature-XRD, and SEM Analyses. Ind. Eng. Chem. Res. 2013; 52:36833692.

4. Wagner D, Devisme O, Patisson F, Ablitzer D. A laboratory study of the reduction of iron oxides by hydrogen. Sohn Int. Sym. 2006; 2:111-120.

5. Pineau A, Kanari N, Gaballah I. Kinetics of reduction of iron oxides by $\mathrm{H} 2$ Part I: Low temperature reduction of hematite. Thermochimica Acta 2006; 447: 89-100.

6. Pineau A, Kanari N, Gaballah I. Kinetics of reduction of iron oxides by H2 Part II: Low temperature reduction of magnetite. Thermochimica Acta 2007; 456:75-88.

7. Lin $\mathrm{H}$, Chen $\mathrm{Y}$, Li C. The mechanism of reduction of iron oxide by hydrogen. Thermochimica Acta 2003; 400:61-67.

8. Mondal K, Lorethova H, Hippo E, Wiltowski T, Lalvani S B. Reduction of iron oxide in carbon monoxide atmosphere-reaction controlled kinetics. Fuel Processing Technology 2004; 86:33- 47. 
9. Bonalde A, Henriquez A, Manrique M. Kinetic Analysis of Iron Oxide Reduction Using Hydrogen-Carbon Monoxide Mixtures as Reducing Agent. ISIJ International 2005; 45:1255-60.

10. Mattisson $T$, Lyngfelt $A$, Cho $P$. The use of iron oxide as an oxygen carrier in chemical-looping combustion of methane with inherent separation of $\mathrm{CO}_{2}$. Fuel 2012;80: 1953-1962.

11. Mattisson T, Johansson M, Lyngfelt A. Multicycle Reduction and Oxidation of Different Types of Iron Oxides Particles - Application to Chemical-Looping Combustion. Energy \& Fuels; 2004; 18:628-637.

12. Piotrowski K, Mondal K, Lorethova H, Stonawski L, Szymański T, Wiltowski T. Effect of gas composition on the kinetics of iron oxide reduction in a hydrogen production process. I. Journal of Hydrogen Energy; 2005;30:1543-1554.

13. Fruehan $\mathrm{R} J$. The Rate of Reduction of Iron Oxides by Carbon. Metallurgical Transactions B; 1977; 8B:279-286.

14. Tiernan M, Barnes P, Parkes G M B. Reduction of Iron Oxide Catalysts: The investigation of Kinetic Parameters Using Rate Perturbation Linear Heating Thermoanalytical Techniques. J. Phys. Chem B; 2001; 105:220-228.

15. Turkdogan E T, Vinters J V. Gaseous Reduction of Iron Oxides: Part I. Reduction of Hematite in Hydrogen. Metallurgical Transactions; 1971; 1:3175-3188.

16. Turkdogan E T, Olsson R G, Vinters J V. Gaseous Reduction of Iron Oxides: Part II. Pore Characteristics of Iron Reduced from Hematite in Hydrogen. Metallurgical Transactions; 1971; 2:3189-3196.

17. Turkdogan E T, Vinters J V. Gaseous Reduction of Iron Oxides: Part III. Reduction-Oxidation of Porous and Dense Iron Oxides and Iron. Metallurgical Transactions; 1972; 3:1561-1574.

18. Sastri M V C, Viswanath R P, Viswanathan B. Studies on the Reduction of Iron Oxide with Hydrogen. Int. J. of Hydrogen Energy; 1982; 7:951-955.

19. Singh A, Al-Raqom F, Kluasner J, Petrasch J. Production of hydrogen via an Iron/Iron Oxide Looping Cycle : Thermodynamic Modeling and Experimental Validation. I. Journal of Hydrogen Energy 2012; 37: 7442-7450.

20. Svoboda K, Slowinski G, Rogut J, Baxter D. Thermodynamic possibilities and constraints for pure hydrogen production by iron based chemical looping process at lower temperatures. Energy Conversion and Management 2007; 48:30633073.

21. Yuan J, Wang W, Zhu S, Wang F. Comparison between oxidation of iron in oxygen and in steam at 650-750 ${ }^{\circ} \mathrm{C}$. Corrosion Science 2013; 75:309-317. 
22. Nakai M, Nagai K, Murata Y, Morinaga M, Matsuda S, Kanno M. Corrosion of high temperature steam oxidation with hydrogen dissolution in pure iron and ternary high-chromium ferric steel. ISIJ International 2005; 45:1066-1072.

23. Signorini L, Pasquini L, Savini L, Carboni R, Boscherini F, Bonetti E. Size dependent oxidation in iron/iron oxide core shell nanoparticles. Physical Review B 2003; 68: 195423.

24. Kuhn L T, Bojesen A, Timmermann L, Nielsen M M, Morup S. Structural and magnetic properties of core-shell iron-iron oxide nanoparticles. Journal of Physics: Condensed Matter 2002; 14:13551-13567.

25. Bahgat $\mathrm{M}$, Khedr $\mathrm{M} \mathrm{H}$. Reduction kinetics, magnetic behavior and morphological changes during reduction of magnetic single crystal. Material Science and Engineering B 2007; 138:251-258.

26. Appl M. Ammonia: principles and industrial practice. Wiley-VCH 1999; 9:35-63.

27. Go K S, Son S R, Kim S D. Reaction kinetics of reduction and oxidation of metal oxides for hydrogen production. I. Journal of Hydrogen Energy 2008; 33:5986-95.

28. Jung S S, Lee J S. In-situ kinetic study of hydrogen reduction of $\mathrm{Fe}_{2} \mathrm{O}_{3}$ for the production of Fe nanopowder. Material Transactions 2009; 50:2270-76.

29. Jozwiak W K, Kaczmarek E, Maniecki T P, Ignaczak W, Maniukiewicz W. Reduction behaviors of iron oxides in hydrogen and carbon monoxide atmospheres. Applied Catalysis A 2007; 36:17-27. 


\section{Appendix}

\section{A. Derivation of substrate conservation equation}

According to the definition of fractional conversion of the reactive substrate,

$$
\begin{gathered}
x_{i}(t, z)=\frac{\text { Mass of reactive substrate } \mathrm{i}, \text { reduced to lower oxide }(\mathrm{t}, \mathrm{z})}{\text { Initial mass of reactive substratei, }(\mathrm{z})} \\
\frac{d x_{i}}{d t}=\frac{\frac{d}{d t}\{\text { Mass of reactive substratei, reduced to lower oxide }(\mathrm{t}, \mathrm{z})\}}{\text { Initial mass of reactive substratei }(\mathrm{z})} \\
\frac{d x_{i}}{d t}=\frac{\frac{d}{d t}\left\{n_{i} M_{i}\right\}}{m_{i}}
\end{gathered}
$$

According to Eq. 2 and 3, for every mole of steam generated during reduction, one mole of reactive substrate, magnetite or wustite is consumed. Therefore,

$$
\frac{d n_{i}}{d t}=\frac{d n_{\text {steam }}}{d t}
$$

Eq. 4 governs the rate at which moles of steam are generated per unit reactor volume. Thus, the rate at which moles of steam generated are in a specific control volume is given as,

$$
\frac{d n_{\text {steam }}}{d t}=\dot{r} V_{C V}
$$

Combining Eqs. A.3, A.4 and A.5,

$$
\frac{d x_{i}}{d t}=\beta_{i} k_{o, i} \exp \left(-E a_{i} / R T\right) f\left(x_{i}\right) C_{j}^{n}
$$

where,

$$
\beta_{i}=\frac{M_{i} V_{C V}}{m_{i}}
$$

Note that the available mass of wustite is a function of time and space (Eq. 18). However, the temporal dependence of available mass of wustite is applicable in a global time domain only. Fractional conversion of the reactive substrate is computed in each time step (local time domain), and the available mass of wustite (equivalent to the initial mass of magnetite, Eq. 17) is constant in the local time domain. Thus, the computation 
of fractional conversion wustite does not require different mathematical treatment compared to that of magnetite, and the substrate conservation equation can be implemented for magnetite as well as wustite.

\section{B. Determination of unknown coefficients of apparent density distribution function.}

The specified physical constraints used to evaluate the unknown coefficients in Eq. (9) are:

1. During the oxidation step, iron at the reactor bed inlet is completely converted into magnetite,

$$
\rho^{*}{ }_{\mid \eta=0}=1
$$

2. The apparent density is maximum at the reactor bed inlet,

$$
{\frac{d \rho^{*}}{d \eta_{\mid \eta=0}}}_{\mid=0}=0
$$

3. The apparent density is minimum at the reactor bed outlet,

$$
{\frac{d \rho^{*}}{d \eta_{\mid \eta=1}}}_{\mid=0}
$$

4. Mass within the reactor is conserved, and the mass, $m$, of magnetite at the conclusion of the oxidation step is

$$
\int_{\eta=0}^{\eta=1} \rho * d \eta=\frac{m}{m_{\max }}
$$

where $m_{\max }$ is the mass of magnetite that would be present in the bed if there were complete conversion of the bed from iron to magnetite.

The physical constraints used to determine the unknown coefficients in Eq. (9) are summarized in Table B.1. Table B.2 lists the apparent density function of magnetite at the beginning of the reduction step for all operating conditions. 
Table B.1. Specified physical constraints used to determine the unknown coefficients of the cumulative mass fraction expression for magnetite.

\begin{tabular}{|c|c|}
\hline No & Magnetite \\
\hline 1 & $\rho_{\mid \eta=0}^{*}=1$ \\
\hline 2 & $\frac{d \rho^{*}}{d \eta} \eta_{\eta=0}=0$ \\
\hline 3 & ${\frac{d \rho^{*}}{d \eta_{\eta=1}}}^{*}=0$ \\
\hline 4 & $\int_{\eta=0}^{n=1} \rho^{*} d \eta=\frac{m}{m_{\max }}$ \\
\hline
\end{tabular}

Table B.2. Apparent density distribution function for each cycle.

\begin{tabular}{|c|c|l|}
\hline $\begin{array}{l}\text { Cycle } \\
\text { No. }\end{array}$ & $\begin{array}{l}\text { Dimensionless, initial mass of } \\
\text { magnetite }\left(\frac{m}{m_{\max }}\right)\end{array}$ & $\begin{array}{l}\text { Apparent density distribution } \\
\text { function } \\
\rho^{*}=a \eta^{3}-b \eta^{2}+1\end{array}$ \\
\hline 1 & 0.76 & $\mathrm{a}=0.9796, \mathrm{~b}=1.4694$ \\
\hline 2 & 0.77 & $\mathrm{a}=0.9388, \mathrm{~b}=1.4082$ \\
\hline 3 & 0.79 & $\mathrm{a}=0.8571, \mathrm{~b}=1.2857$ \\
\hline 4 & 0.77 & $\mathrm{a}=0.9388, \mathrm{~b}=1.4082$ \\
\hline 5 & 0.82 & $\mathrm{a}=0.7347, \mathrm{~b}=1.102$ \\
\hline 6 & 0.85 & $\mathrm{a}=0.6122, \mathrm{~b}=0.9184$ \\
\hline 7 & 0.84 & $\mathrm{a}=0.6531, \mathrm{~b}=0.9796$ \\
\hline
\end{tabular}

Figure B.1 shows the non-dimensional apparent density distribution of magnetite in the reactor at the beginning of the reduction step for cycle 1 ; for all other operating conditions, the apparent density follows a similar form. 


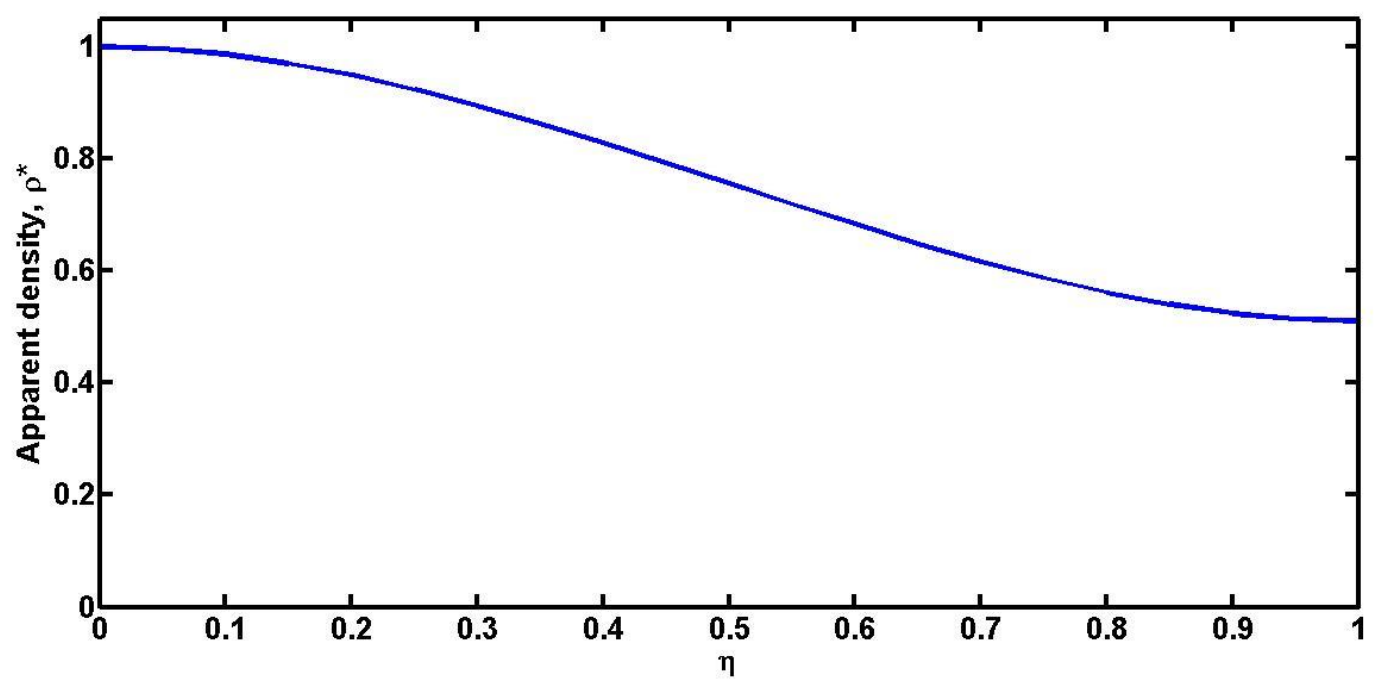

Figure B.1. Apparent density distribution of magnetite within the reactor at the beginning of the reduction step for cycle 1 . 